San Jose State University

SJSU ScholarWorks

Doctoral Projects

Master's Theses and Graduate Research

Spring 5-2017

\title{
Curriculum Development of California Correctional Institution (CCl) Nursing Staff Performance during Simulation Training Related to Cardiac Emergency Response
}

Dina Wang

California State University, Northern California Consortium Doctor of Nursing Practice

Follow this and additional works at: https://scholarworks.sjsu.edu/etd_doctoral

Part of the Other Nursing Commons

\section{Recommended Citation}

Wang, Dina, "Curriculum Development of California Correctional Institution (CCI) Nursing Staff Performance during Simulation Training Related to Cardiac Emergency Response" (2017). Doctoral Projects. 65. DOI: https://doi.org/10.31979/etd.4c78-j3qp https://scholarworks.sjsu.edu/etd_doctoral/65

This Doctoral Project is brought to you for free and open access by the Master's Theses and Graduate Research at SJSU ScholarWorks. It has been accepted for inclusion in Doctoral Projects by an authorized administrator of SJSU ScholarWorks. For more information, please contact scholarworks@sjsu.edu. 


\section{ABSTRACT \\ CURRICULUM DEVELOPMENT OF CALIFORNIA CORRECTIONAL INSTITUTION (CCI) NURSING STAFF PERFORMANCE DURING SIMULATION TRAINING RELATED TO CARDIAC EMERGENCY RESPONSE}

The Cycle 4 OIG medical reports published in January 2016 for California Correctional Institution (CCI) noted emergency medical response (EMR) inadequacies. Nursing was specifically called out for EMR care deficits. Chest pain and respiratory distress were amongst the top signs and symptoms identified as having substandard nursing care issues within the report. The cycle 4 OIG medical inspection report gives specific incidences of patient care inadequacies.

As a result of the EMR portion results of the cycle 4 OIG reports, there was a need for improvement planned interventions. The Doctor in Nurse Practice (DNP) project is a quantitative quasi-experimental study used to evaluate the EMR performance of the CCI nursing staff population. The research question being addressed: does simulation-based training increase correctional nursing staff performance during cardiac emergency response scenarios? The design/methodology of the research included 40 nurse participants that were placed into teams of five and given a cardiac EMR scenario simulation training with a pre and post-test associated. There were a total of eight identical simulation sessions that were offered as one session per day. The pre-test was completed before the simulation training and the post-test was given after the simulation scenario. A debrief discussion was conducted at the end of each simulation training team experience. The pre and post-test included critical thinking type questions related to cardiac EMR using primarily close-ended questions and a few 
open ended questions (Ex. How do you feel about simulation training?) for feedback purposes. During the simulation training, nurses were evaluated on their performance factors of nursing skills, teamwork, critical judgement and interrelational effective communication.

This research was valuable to improving the EMR performance skills for $\mathrm{CCI}$ correctional nurses. The goal is to provide proficient, quality health care, improve patient outcomes, and eventually achieve adequate OIG passing scores for EMR. The data analysis method used for this study was paired sample t-test through software system SPSS version 24. The post-test for the simulation training was using a dependent variable while the pre-test measure would be the covariate. The pre-test would not be considered an outcome. The paired sample t-test measures were assessed for differences in the post-test means after accounting for the pre-test values. The values produced from the paired sample t-test focused on whether the one group had higher means after the simulation training experience showing research significance.

Dina Wang

May 2017 



\title{
CURRICULUM DEVELOPMENT OF CALIFORNIA CORRECTIONAL INSTITUTION (CCI) NURSING STAFF PERFORMANCE DURING SIMULATION TRAINING RELATED TO CARDIAC EMERGENCY RESPONSE
}

\author{
by \\ Dina Wang DNP (c), CCHP, RN
}

\author{
A project \\ submitted in partial \\ fulfillment of the requirements for the degree of \\ Doctor of Nursing Practice \\ California State University, Northern Consortium \\ Doctor of Nursing Practice
}

May 2017 


\section{APPROVED}

\section{For the California State University, Northem Consortium Doctor of Nursing Practice:}

We, the undersigned, certify that the project of the following student meets the required standards of scholarship, format, and style of the university and the student's graduate degree program for the awarding of the master's degree.

Dina Wang

Project Author

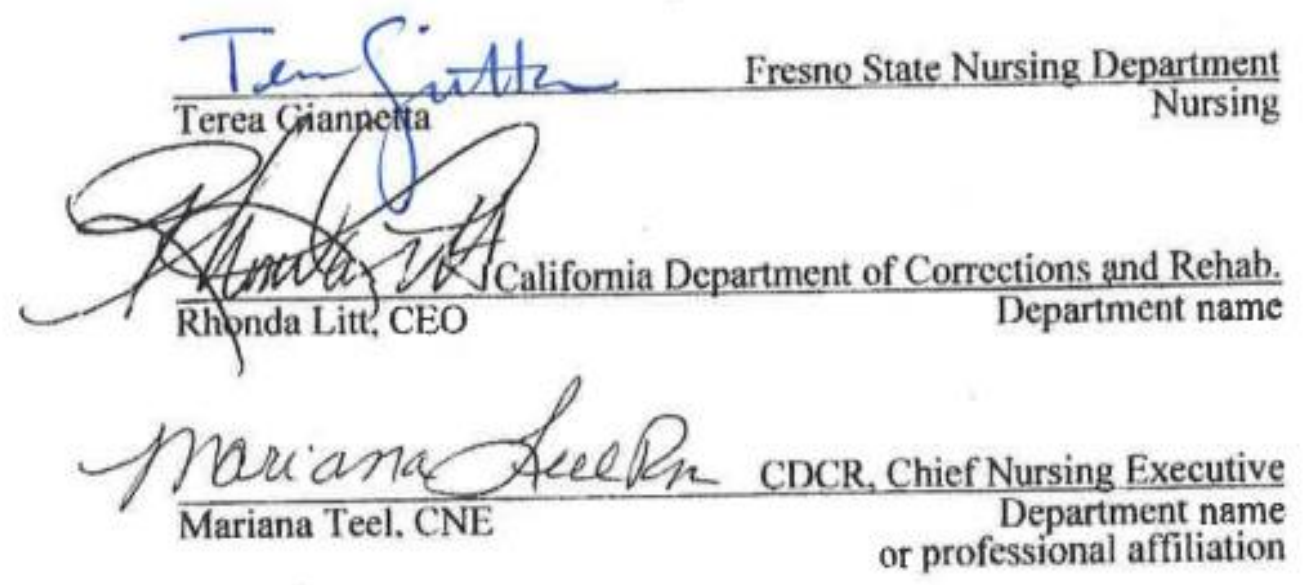




\section{AUTHORIZATION FOR REPRODUCTION}

\section{OF DOCTORAL PROJECT}

X I grant permission for the reproduction of this project in part or in its entirety without further authorization from me, on the condition that the person or agency requesting reproduction absorbs the cost and provides proper acknowledgment of authorship.

Permission to reproduce this project in part or in its entirety must be obtained from me.

Signature of project author: 


\section{ACKNOWLEDGMENTS}

I would like to express the deepest appreciation to my committee chair Dr. Terea Giannetta and advisor Dr. Christine Ortiz. They have provided continual support and guidance through the DNP program that has led to my academic success. The Fresno State faculty members have shown dedication to education and tremendous commitment to students learning progression. Without the leadership and persistence in the directions that I have received, this DNP project would not have been possible.

I would like to thank my committee members, Mariana Teel, Former Chief Nursing Executive and Rhonda Litt, Chief Executive Officer at California Correctional Institution. They embraced the concept of advanced nursing practice and provided collaboration expertise to introduce innovative educational methods to correctional nurses. Through their confidence and backing, the nursing education department was able to build an entire simulation lab with high-fidelity equipment beneficial to nursing development.

Also, a thank you to the California Department of Corrections and Rehabilitations (CDCR) Office of Research and Committee for the Protection of Human Subjects (CPHS) individuals who made this DNP research achievable. Their cooperation and timely responses were of great assistance to maintaining the stringent DNP timeline.

I thank Fresno State University School of Nursing for all of their hard work in providing a Doctor in Nurse Practice program that has the potentials of contributing valuable changes to health care through nurses. 


\section{TABLE OF CONTENTS}

Page

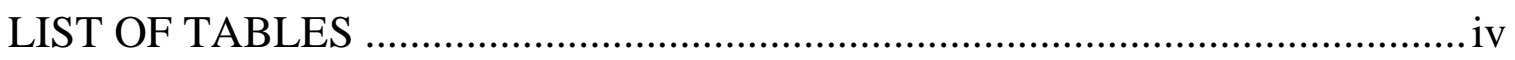

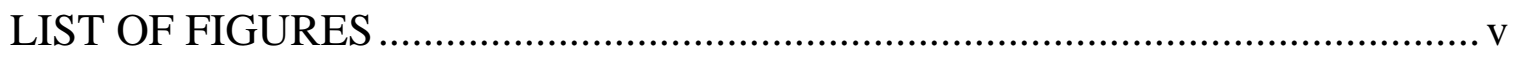

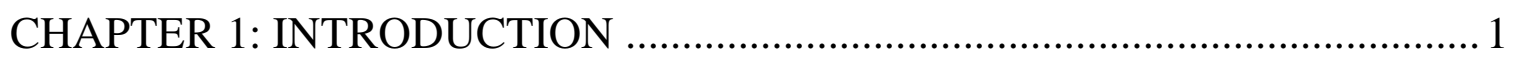

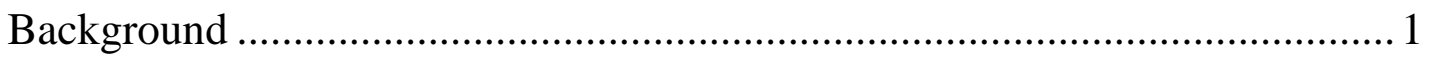

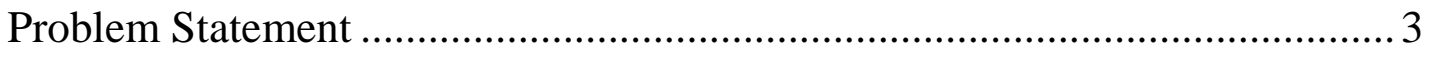

Purpose of the Project ................................................................................. 4

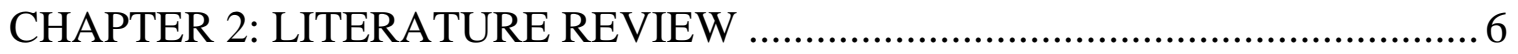

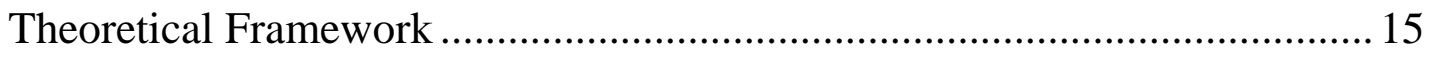

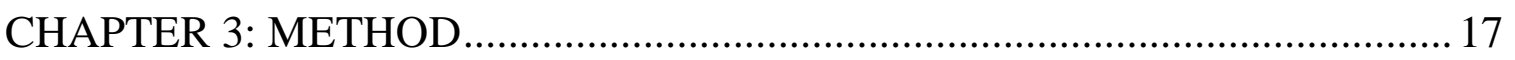

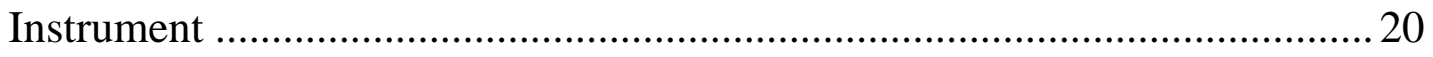

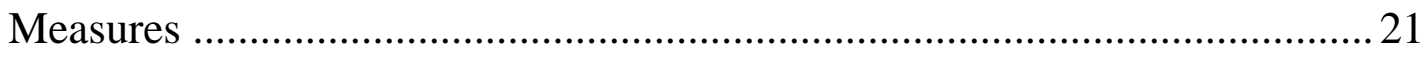

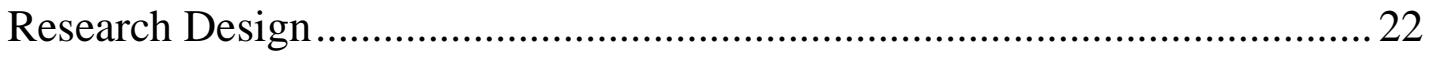

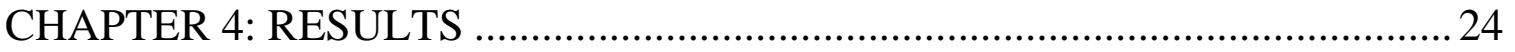

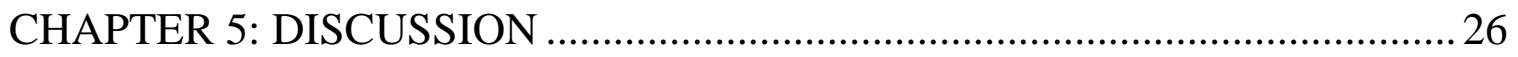

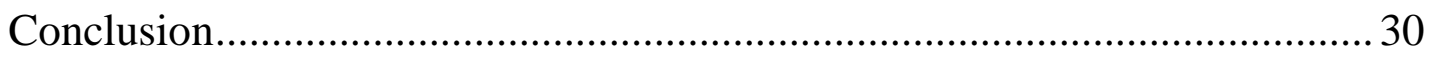

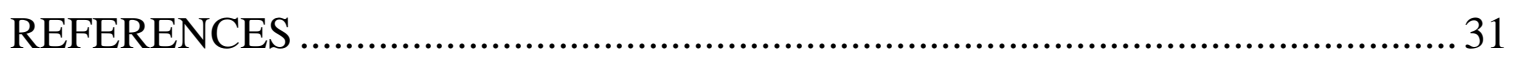

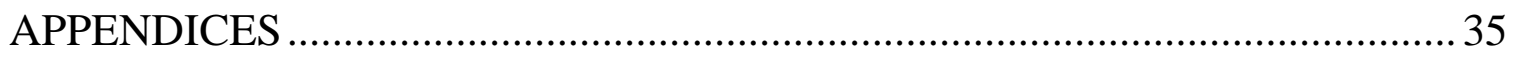

APPENDIX A: ORAL PRESENTATION POWERPOINT ................................... 36

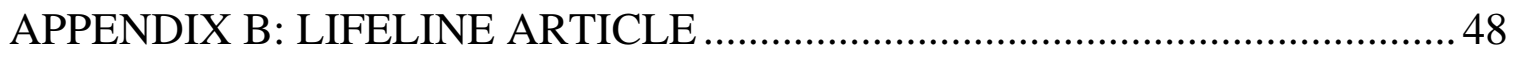

APPENDIX C: CDCR RESEARCH APPROVAL LETTER...............................51

APPENDIX E: HIGH FIDELITY SIMULATION SCENARIO SCRIPT ............56

APPENDIX F: PRE AND POST-TEST RESEARCH TOOL..............................64 APPENDIX G: NURSING PARTICIPANT RESEARCH CONSENT FORM....71 


\section{LIST OF TABLES}

Page

Table 1 California Correctional Institution Nursing Population Data for All

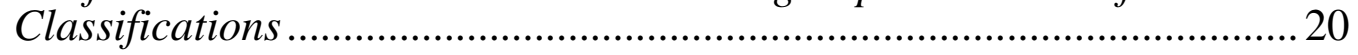




\section{LIST OF FIGURES}

Page

Figure 1. Pre and post-test scores for nurses who completed high-fidelity

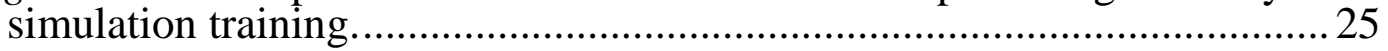




\section{CHAPTER 1: INTRODUCTION}

Correctional nursing has been in effect as a specialty since 1976. The United States Supreme Court ruled in the Estelle v. Gamble (1976) case that failure to provide adequate health care while a person is incarcerated violated their constitutional rights (Rold, 2008). Today, California Department of Corrections and Rehabilitations (CDCR) consists of 35 institutions, and 13 adult community correctional facilities that currently house approximately 165,000 adult offenders (cdcr.gov, 2015). Each of the 35 institutions has a well-rounded, resourceful correctional healthcare team that cares for the incarcerated population. The medical team is equipped with surgeons, providers, nurses, and specialty services that offer complete health care resources. Correctional nurses are the largest health care provider network within the CDCR prison settings. Nurses are expected to handle emergencies, triage, case-management, and manage chronic care needs. There has been little research conducted with correctional nurses using simulation training to improve upon the emergency response of patient care. This study was undertaken to develop nurses' abilities to better prepare for handling emergency medical response (EMR) through simulation training specifically relating to cardiac emergencies.

\section{Background}

The Federal Receivership took over jurisdiction of CDCR in 2005 due to the lack of adequate care provided to incarcerated patients (Los Angeles Times, 2015). During this last decade, there has been increased efforts from many governing entities and political decision makers involved with the massive improvement in patient care standards. The institutional efforts have led to 
medical clinic re-constructions, the addition of telemedicine, new state of the art medical equipment, and refraining from fiscal spending restrictions to patients in need of medical care. California Correctional Health Care Services (CCHCS) is the division within CDCR that regulates standardized health care practices for all the institutions. This division is responsible for the clinical practice policies and procedures that translates into the care for incarcerated individuals. The CDCR 2016-2017 fiscal year budget report projections for the adult prison population medical services will be approximately $\$ 1.73$ billion dollars ("CDCR Budget Information," 2016). These funding figures excludes the expenditures for juvenile healthcare, dental and mental health services.

The Office of Inspectors General (OIG) is the state quality agency responsible for overseeing the inmate health care program put out by CCHCS. This sector conducts ongoing monitoring and select reviews of policies, practices, and procedures of CDCR/CCHCS. The OIG reports to the Federal Receivership ensuring healthcare compliance. This is the equivalency to the relationship between the Joint Commission on Accreditation of Healthcare Organizations (JCAHO) and private-sector hospitals. Office of Inspectors General represents the largest team of civilian auditors governing over 300 divisions of government programs. It is considered the premier health care law enforcement agency source. Annual medical reports are generated for each institution based on overall performance of health care qualities provided to inmates.

Additional to the Federal and State quality measures are several inmate class action lawsuits against correctional healthcare services resulting in the change of correctional medical care practices. Armstrong, Clark, Coleman, and Plata inmate cases are amongst some well-known trials that have evolved correctional care into the current clinical practices ("Background Class Action 
Lawsuits," 2012). These litigations identified deficits in the prison health care system lapsing accessibility to reasonably accommodating inmates with physical, developmental disabilities, mental health issues, and implementation of medical reform within the prison system ("Background Class Action Lawsuits," 2012). All of these divisions affect clinical practice and regulate mandatory patient care procedures from all aspects.

Each of the 35 institutions has a Nurse Education Department and InService Training Department (IST) that oversees the annual training that is required for all medical staff. Through mandatory regulations, nurses must complete annual training on various policy updates, procedure, protocol, skills, prison safety and awareness that is scheduled throughout the year. Recently, Nursing Education and IST have initiated additional web-based learning and other technology techniques to maximize training efforts. Education for nurses has now expanded to using classroom settings, training arena, simulation lab, and intranet module resources. The training arena is an indoor location away from inmate activity that is equipped with custody gear apparatus for scenario training. This arena is where medical and custody collaborate in creating simulated inmate chaotic situations and require immediate appropriate reactions from staff individuals in those instances.

\section{Problem Statement}

Currently, there is no standardized simulation EMR training for all CDCR institutions. The training curriculum is at the discretion of each institution for translation, and therefore education at one facility does not equivocate to the next. Although, this is a work in progress, there is much to be developed for standardized education curriculums. All institutions also have various level of 
security inmate populations which affect the EMR dealt with at each facility. The learning equipment varies depending on the nurse education and IST departments. Education components and equipment can vary depending on each institutions preference decisions. California Correctional Institution (CCI) is one of the 35 institutions located in Tehachapi, California. The population of interest in this study are the registered nurses, licensed vocational nurses, and licensed psychiatric technicians employed at this particular facility.

In 2015, the OIG performed the Cycle 4 medical inspection for CCI reviewing 415 patient-inmate files. It also covered 93 objectively scored tests of compliance with CCHCS policy and procedures applicable to the delivery of inmate medical care. Of these reviewed patient cases, it was noted that CCI received an overall assessment rating of "adequate." However, an "inadequate" score was given for the emergency medical services section of the report. OIG clinicians reviewed 63 urgent/emergent events and found 52 deficiencies mainly in the area of nursing care (Barton, 2016).

\section{Purpose of the Project}

As a result of low scoring relating to EMR in the Cycle 4 CCI medical report from OIG, an improvement plan was initiated to make specific changes to health care delivery practices. The medical management team at CCI has set in motion a concept plan to improve quality care nursing standards. The purpose of this research was one innovative contribution from the nursing education department. The goal was to improve nursing emergency response skills and increase the institution's OIG EMR score by implementing constructive changes to nursing practice. The educational efforts will incrementally stimulate nurse learning interest and in turn indirectly effect the health care quality. With a goal 
and vision, collectively the CCI will succeed in continuing as a leading role model institution.

The DNP research was able to evaluate correctional nursing staff performance during simulation training related to a cardiac emergency. The aims of the study used a written emergency mock code scenario that required nursing staff to work together and provide appropriate interventions for patient care. The simulation training evaluated correctional nursing performance (critical judgment, skills, teamwork, and inter-relational effective communication) during an EMR cardiac ventricular fibrillation scenario. The outcome was measured by using closed-ended questions in a pre-test before simulation training and comparing to a post-test scores after simulation training. The purpose was using innovative high fidelity simulation (HFS) training to provide hands-on, real-life training to effectively prepare correctional nurses for handling cardiac emergencies. 


\section{CHAPTER 2: LITERATURE REVIEW}

There have been limited studies conducted within correctional nursing. With the identified needs for improvement through OIG's medical report, the DNP project is one approach for a resolution to the issue and contribution to correctional nursing research. There is abundant literature relating to nursing students and the beneficial use of simulation training. Being able to bring that knowledge into a classroom setting for the CDCR nursing staff could potentially assist in the critical thinking and performance development necessary to positively impact cardiac emergency patient outcomes. Currently, there are also limited amounts of research that have been initiated specific to correctional nursing training curriculum development in general. Diaz et al. (2014) is amongst some of the most recent introductory simulation research conducted with nurses in a prison setting with optimistic results. However, increasing the amounts of correctional nursing advanced research could potentially impact improvements measures for nursing quality care standards. With the DNP study, one goal was to bridge the gap between CDCR practices and the beneficially proven nursing student simulation research studies to make significant differences in correctional nurse learners.

In the Forneris et al. (2015) research, a quasi-experimental study on developing sound critical thinking and reasoning skills through simulation debriefing was conducted. The researchers used student nurses at four faith-based baccalaureate private colleges of nursing in the Midwest. Consistency was ensured with research methods, procedures, and instruments; a pilot study was conducted the year prior. A pre/post-test repeated measures to answer two research questions. Research Question 1: Does the use of Debriefing for Meaningful Learning (DML) 
positively impact the development of clinical reasoning skills in undergraduate nursing students? Research Question 2: Do nursing students perceive a difference in the quality of debriefing when the DML method is used compared to usual debriefing?

While debriefing is one approach for critical thinking skill development, Cazzell and Anderson (2016) conducted a quantitative cross-sectional descriptive correlational study examining the impact of critical thinking and judgment evaluating 160 pre-licensure nursing students. Students ranged from 20-62 years of age with a median of 25.96 years. Participating senior level undergraduate baccalaureate nursing students were recruited through two semesters. They were engaged in an objective structured clinical examination (OSCE). An unaccompanied videotape session was completed relating to OSCE medication administration as part of the pediatric course requirement. Students encountered a simulator, in-static mode dressed in infant clothing. Data was collected between 2012 and 2013 at a large, ethnically diverse university in the Southwest United States (Cazzell \& Anderson, 2016).

In the Forneris et al. (2015) study, a particular target population of 200 second-year course work students was the sample size targeted obtaining a medium effect size between .50 and .80 percent power. Students were informed verbally and in writing about the research study and provided their consent. Data was collected for the first research question through the Health Sciences Reasoning Test (HSRT) instrument. This was a 33 question, validated, multiple choice test assessing critical thinking skills in health science students and professional health science practitioners. Reliability for the HSRT is established through using Kuder-Richardson-20 calculation for dichotomous multi- 
dimensional scales. Validity was determined by correlating test items to the Delphi Reports along with committee and professional support.

Debriefing Assessment for Simulation in Healthcare-Student Version (DASH-SV) was used to answer the second research question in Forneris et al. (2015). The design of the DASH-SV rates six key elements relating to nursing student perceptions about debriefing quality. It assists with the instructor's ability to establish and maintain a learning environment in an organized manner. The initial reliability of the DASH-SV was done through the original study of Dreifuerst (2012). The original reported findings for the DASH-SV was $0.82(\mathrm{n}=6$, $\mathrm{M}=29.54$, variance $=24.26, \mathrm{SD}=4.93)$. Validity and content for DASH-SV were established by the developers (Simon et al.). The findings for research question 1 pre-test for the intervention group were $(\mathrm{n}=78, \mathrm{M}=22.74, \mathrm{SD}=3.6)$ and control group $(\mathrm{n}=75, \mathrm{M}=22.06, \mathrm{SD}=3.7)$. Post-test after simulation training results were $(n=78, M=23.56, S D=3.9)$ for the intervention group $(n=75, M=22.41$, $\mathrm{SD}=4.6)$ and the control group. Langdorf et al. (2014) discussed that high fidelity simulation (HFS) training is emotionally intense, preferred by students, and has an enhancement to knowledge retention. The debriefing process studied by Forneris et al. (2015) shows that learners make meaningful connections allowing for knowledge retention.

Cazzell and Anderson (2016) used similar tools of multiple choice testing to assist critical thinking and the learning process. The Tower of Hanoi (TOH), Health Science Reasoning Test (HRST), Lasater Clinical Judgement Rubric (LCJR), and OSCE checklist were all instruments used in the study. Students were given the $\mathrm{TOH}$ activity game as a way to increase their critical thinking skills. The HRST was a computer administered 33-item multiple-choice test timed with 50 minutes to complete as a standardized examination of critical thinking skills. 
There were 11 items on the LCJR correlating along with the 14 items of medication administration OSCE checklist measuring clinical judgment scored through the videotaped simulation session. The LCJR was scored while the OSCE checklist was not used for scoring. A prior power analysis for multiple regression was calculated to ensure appropriate sample size.

Cazzell and Anderson (2016) intended to replicate Dreifuerst's (2012) findings of clinical reasoning changes using DML. One research limitation was that only senior students from one university participated limiting the generalizability of the findings (Cazzell \& Anderson, 2016). From the significance shown in each of these studies, the DNP simulation curriculum incorporated multiple-choice testing and debriefing measures for educational learning purposes resulting also in significant findings. Suk Jeong, Sang Suk, and Young-Mi (2015) conducted research in improving effective guidelines for future simulation trainings using a junior nursing student population. Another component added to the simulation training curriculum was the follow-up debriefing effect and students first response experiences. Through the DNP simulation training, performance of CCI nurses were studied specifically in their abilities to increase efficiency and preparation skills for actual cardiac emergencies situations.

Aqel and Ahmad (2014) completed a randomized two-arm trial study using experimental pre/ post-test approaches to examine the effectiveness of highfidelity simulation (HFS) training versus low-fidelity simulation (LFS) relating to the CPR knowledge retention and skills. Second-year nursing students were split into two groups. One group being LFS and another being the intervention HFS education cohort. Students were recruited from the University of Jordan through meeting inclusion criteria's. The majority of the students were female $(\mathrm{N}=71)$, and all participants ranged in age from $18-28$ years $(M=19.87, S D=1.78)$. The setting 
for this study was conducted in the nursing laboratory at the University of Jordan where it was well equipped with dolls, materials, manikins, and high-fidelity simulators. There were 124 nursing students enrolled into the study, but only 90 completed all phases. Participants were randomly assigned into two equal groups (control and intervention). This research had three research hypotheses. Hypothesis \#1: There is no difference between CPR HFS intervention and LFS control groups. Hypothesis \#2: The HFS group will demonstrate a higher level of CPR knowledge than the control group. Hypothesis \#3: The intervention group will retain the high level of knowledge and skills three months after training compared to the LFS group (Aqel \& Ahmad, 2014).

The researchers showed that the grade point (GP) in the control group was higher than the intervention group $(\mathrm{M}=3.09,2.82$, respectively). An independent t-test was used for research hypothesis \#1 revealing no significant difference between the intervention $(M=5.78, S D=1.2)$ and control $(M=5.93, S D=1.15)$ group. For research hypothesis \#2, the results revealed an existence of a difference in the post-test CPR knowledge and skills for the intervention group. Research hypothesis \#3 results were computed through a dependent sample t-test and a paired $t$-test showing a significant difference $(t=8.05 ; p .001)$ in CPR retention skills between the groups $\mathrm{p}<.001$ (Aqel and Ahmad, 2014). Similar findings were noted in a study conducted with junior nursing student's first experiences using HFS as a training tool (Suk Jeong, Sang Suk, \& Young-Mi, 2015).

Another aspect of HFS training is incorporating more innovative approaches to learning verses traditional classroom lectures. Curl et al. (2016) completed a quasi-experimental study to measure the effectiveness of integrated simulation and clinical experiences compared to traditional clinical experiences for nursing students. Three associate nursing programs from different schools 
partnered to identify, implement and evaluate an effective plan of using highfidelity simulation (HFS) to replace 50 percent of traditional clinical experiences in obstetrics, pediatrics, critical care, and mental health nursing. Between the three participating associate programs, Southeast Texas Regional Innovation Project on Effective Simulations (STRIPES) was created as a project using 50 percent HFS incorporated into the clinical experience of the nursing student participant curriculum. One hundred twenty-four students were recruited on a volunteer placing 59 in the STRIPES and 65 in the traditional program.

The instrument used in the Curl et al. (2016) research for data collection was a comprehensive evaluation tool comparing the STRIPES to the traditional students. This incorporation provided a medical-surgical exam that was administered to participants as pre-test and post-test measurements. The STRIPES students participated in weekly central lab groups and completed a series of case study questions. Each simulation training lasted 30-45 minutes followed by a 45minute debriefing. Curl et al. (2016) research discovered that the STRIPES group of students were significantly different in post-test mean scores $(938.56, \mathrm{~F}[1,95]$ $=3.87 . \mathrm{p}=.05)$ than the traditional group $(875.98, \mathrm{~F}[1,95]=6.81, \mathrm{p}=.01)$. Three out of four analyses of covariance showed the STRIPES group were increasingly knowledgeable than the traditional study group. Forneris et al. (2015) also used similar testing tools and debriefing methods that found significance in the learning outcomes of students.

One strength of the Curl et al. (2016) study was utilizing three different ADN programs with a variety of student participants. This is a similar population sample of pre-licensure student populations to Forneris et al. (2015) and Cazzell and Anderson (2016). Simulation training and the effects on nursing students has been studied in many different aspects as examined in the above literature. 
However, with the lack of research in using simulation training for correctional nurses, these studies provide useful literature for the foundational structuring of the DNP educational curriculum development. The DNP research contributes to closing the gap between nursing student opportunities for learning and reinforcing the same learning mechanisms in professional correctional workforce nurses. Liaw et al. (2015) discussed the effectiveness of utilizing simulation training to transition nursing students to practice clinical practicum. Additional to closing the gap from student to workforce, is also introduces new learning techniques for nurses to remain updated on best-practice skills similar to education approaches in the private sector hospitals and academic environments. Scenario-based HFS training with debriefing allows nurses an innovative educational experience differing from traditional classroom teaching methods as discussed by Curl et al. (2016).

From the Aqel and Ahmad (2014) research, low fidelity simulation (LFS) grouped nursing students attended a lecture on CPR and used LFS with static manikins while the intervention group used HFS manikins. A post-test was then conducted immediately following the given CPR knowledge evaluating CPR understanding and skills within a cardiac arrest scenario. One strength of this study is learning more about the effects of HFS training and its influence to retain knowledge. One limitation of this study was the conduction in one location which may change results with additional research completed on this topic (Aqel \& Ahmad, 2014). To further this theory, another study using HFS training with nursing students specific to ACLS ventricular fibrillation was conducted to assess ACLS skills and nursing team response (Langdorf et al., 2014). Through this research, students were found with deficits in every phase of ACLS measures. However, significant improvements in all areas were observed after the student 
completed the simulation training with ACLS instruction. The DNP research recognized these study strengths, and used the high-fidelity simulation highlighted benefits to help correctional nurses improve efficiency in emergency response performance. Through the simulation training experience of the DNP research, similar deficits discussed in the Langdorf et al., (2014) article were also noted in the CCI nursing staff during simulation training.

An empirical research descriptive qualitative study was conducted by Liaw et al. (2015). This study looked at simulation-based learning and the effects on nursing students transitioning to practice experiences. The educators and alumni created the Simulated Professional Learning Environment (SIMPLE) to assist with aligning the education process with actual nursing practice. The SIMPLE program was comparable to the STRIPES group simulation training sessions researched by Curl et al. (2016) which included the approached of training and debriefing methods. The difference in the SIMPLE program was that it offered 15 hours of simulation sessions in three hour increments over five weeks comprised of a learning platform. The method for this study was conducting focus groups with 22 final year nursing students in 2012 who completed transitions to practice clinical practicums. Nursing students were recruited at a university in Singapore with the criteria of completing the nine-week SIMPLE program.

Three focus groups with 6-8 members conducted sessions lasting 60-90 minutes. A research team member used an interview guide with four open-ended questions as the data collection tool. All focus group interviews were audiorecorded and transcribed. The Liaw et al. (2015) study had the same research team members facilitating the three focus groups maintaining its dependability. The SIMPLE study resulted in three important findings of experiencing the role of a staff nurse, learning "how to", and gaining knowledge from seniors nurses. One 
strength of this study is approaching academic change to bridge the gap between student and nursing workforce. One limitation of the SIMPLE program looked at students' transition to practice, but limited to the students' perceptions and experiences (Liaw et al., 2015). However, the student perceptions and experiences were further studied by Suk Jeong, Sang Suk, and Young-Mi (2015). The DNP project drew from the strength of all these studies. Through curriculum development of the DNP project, multiple choice and an open-ended question were added on the pre and post-test including a debriefing session to the simulation training experience. This allowed correctional nurses to express their feedback, sharing perceptions, and retaining knowledge from the group debriefing session enhancing each learner's educational experience.

The DNP Project: Curriculum development of California Correctional Institution (CCI) nursing staff performance during simulation training related to cardiac emergency response focuses on continuing progressive research relating to HFS. Instead of the nursing student population, the DNP study uses these similar concepts of HFS to influence the correctional nursing population. These various research studies have shown the various focuses of how simulation-based training validates toward nursing students. From the result findings of each study, there is a strong correlation that HFS training influences positive learning outcomes. Some of the strengths mentioned in the nursing student studies were the success of using sufficient quantities of nursing student participants and ample time periods to examine a particular aspect of education effectiveness. The limitations discussed sample populations being one-dimensional (i.e. using primarily senior students) or only studying one location which perhaps if expanded can contribute to additional research findings. 
HFS is one of the innovation resources that has been introduced to the CDCR-CCI nursing education curriculum for potential benefits to improving patient care standards. By conducting this DNP project study, it provides one additional aspect of HFS and the uses to advance the nursing field with correctional nurses as the primary sample population. This was accomplished by the data collection results that sufficiently answers whether HFS training beneficially improves correctional nursing performance during cardiac emergencies. The study can additionally be used as a reference for future research advancements, and contribute to the current limited amounts of research that focuses on correctional nursing education enhancements.

\section{Theoretical Framework}

The theoretical framework used for this project was Patricia Benner's Novice to expert nursing concept (Benner, 1982). It is a concept that uses five increasing levels of advancement for nurses. Every nurse starts as a nursing student who progresses to the work environment. The nursing student then becomes a professional novice nurse, and gains experience moving towards higher levels of advanced beginner, competent, and proficient nursing care. At the top level is the expert nurse whom develops over time through skills and understanding of patients (Benner, 1982). It requires a strong educational base and a wealth of experiences.

Benner proposed that one could gain the skills and knowledge without ever learning this theory (Benner, 2011). However, the researcher uses it as a foundational building block to monitor nurse learner improvements over time. By using the Novice to expert nursing concept as the framework for HFS training, each nurse can find the appropriate current level of nursing and build upon the 
level as they learn in a simulation lab environment along with peer support, nurse instructor guidance, and away from the incarcerated patient population. The development of knowledge for nursing is composed of practical knowledge, research, and clinical experiences. Experience in nursing skills is a prerequisite to becoming an expert nurse (Benner, 2011).

Benner's Novice to expert classifications are influential to the education and provision of care at the California Department of Corrections and Rehabilitations (CDCR), and useful to the nursing care population at California Correctional Institution (CCI). The nurses at CDCR-CCI come from diverse expertise and educational backgrounds which provide a variety of nursing care abilities. These different credentials place nurses on various levels of knowledge dependent on nursing care experiences and backgrounds. CDCR employment contracts require correctional nurses to work all nursing posts (Ex. emergency, chronic, primary care) interchangeably regardless of skill level.

The nurse instructor identifies challenges in the attempt of bringing all correctional nurses to an expert nurse level due to the variance in nursing backgrounds. The identification of improvement need areas are continually assessed through interventions, needs assessments and educational curriculum development. Aside from HFS training, the nursing education department has develop coinciding curriculums to promote enhanced learning opportunities including interactive web modules, weekly skills labs, and guest speakers. Through this portion of the nursing education developed curriculum, nurses can be measured at their current level of the Benner's concept and work towards gaining higher levels of expert achievements progressively. 


\section{CHAPTER 3: METHOD}

The research method for this project was a quantitative, quasi-experimental method used to evaluate participating nurses at the selected local institutional facility. This involved a group of nursing individuals upon which a variable was tested without any random pre-selection processes. The design was chosen to allow nurses an opportunity to participate in a learning experience through selfwilling recruitment. A pre/post-test was used to evaluate the knowledge of nursing staff prior and immediately after a given scenario on cardiac emergency using simulation training. The pre-test had a pre-comprehension checklist for the individual participants to complete followed by a series of cardiac emergency questions that center on cardiac arrhythmias, specifically ventricular fibrillation emergency situation. The last question in the pre-test was an open-ended question asking staff about their experiences using simulation training as a learning tool. Each person was able to express different thoughts and share perspectives of the HFS training experience.

The nursing staff was paired into groups of five individuals during the scenario and given roles to play during the simulation experience. The five characters were broken down into the primary treatment and triage registered nurse (TTA-RN), the secondary RN or a supervising registered nurse, a licensed vocational nurse or a licensed psychiatric technician, and a secondary licensed vocational nurse or licensed psychiatric technician, and the scribe. There were other observers in the room including custody officers and a medical doctor that were invited and welcomed for observing purposes, but were not included as part of the DNP research project collected data. The mock code scenario was used with the proper equipment of a simulation lab including a HFS mannequin, crash cart, 
cardiac monitor, and practice medications. The practice medications were purchased from a nursing education company that specializes in simulating actual emergency care medications for realism effect.

The high-fidelity mannequin model purchased was the Mega Code Kelly with Advanced SimPad from Laerdal in 2016 through multi-layers of CDCR department approval. This technology equipped mannequin allowed for 3- lead cardiac connections and projected live rhythms onto a monitor during the mock simulation code. Nursing staff was also able to start Intravenous (IV) access on the mannequin with artificial blood features the flowed through the arm. There was also accommodations for actual medication administrations through various routes of IV or Intramuscular (IM). The simulation mannequin had palpable pulses and audible with optional changing cardiac and pulmonary sounds for nurses to utilize as part of the nursing assessments. These features could be controlled through the Wi-Fi SimPad from a distance. Mega Code Kelly had an embedded microphone that the nursing education office technician used to speak through the mannequin as if the patient was verbally responding.

These effects allowed ventricular fibrillation mock code to become a more life-like situation and the opportunity for nurses to practice all necessary intervention skills. The necessary equipment of IV start kits, fluids, medications, crash cart, airways, and cardiac monitors were all supplied to each group of nurses participating in the scenario. Since the script was written that the mannequin loses consciousness requiring the initiation of CPR after arriving at the Treatment/Triage Clinic, the mannequin was dressed by using blue oil-based paint and coloring to tint the lips and fingers blue simulating a cyanotic symptom. The scenario lasted approximately 10-15 minutes depending on the group's teamwork performance. 
Once the scenario was completed, the nursing staff were asked to take an individual post-test having the same questions as the pre-test except for an alternate open-ended question at the end. The open-ended question gave nursing staff an opportunity to communicate what could have been done differently for a better learning experience. The pre/ post-tests scores were entered as data for a paired sample t-test to see if there was significant change using the Statistical Package for the Social Sciences (SPSS) program version 24.

Following each simulation session group, nurses had a 20-30 minute debriefing session to reflect upon the simulation based training experience. Directly after the training, the team of nurses were given time to de-escalate emotions from the simulation training without the nurse instructor present. The nurse instructor was then re-introduced into the room to re-focus the participating group into discussing the learning experience and feedback. All nursing groups of five received the same cardiac ventricular fibrillation scenario and participated in a debriefing process as part of the study.

The study subjects at CCI included willing participants of the Supervising Registered Nurses (SRNII), Registered Nurses (RN), Licensed Practical Nurses (LPN), and Licensed Psychiatric Technicians (LPT) classifications. The planned interventions were recruited with management's assistance in gaining nursing members who expressed interest in simulation training. Participants were notified verbally and in writing the studies purpose. Any nursing staff questions were answered accordingly either verbally or by email prior to HFS training session beginning. There were flyers and posters posted in the nursing clinic bulletin boards for recruitment purposes. The total study size was 40 nurse participants divided into groups of five over eight different sessions. The groups of five nurses 
are realistic to the available assistance that is present in the clinics during an actual emergency medical response on day shifts.

Nurses were given the opportunity to participate in a cardiac emergency medical response scenario simulation training with the pre and post-test associated. The scenario was written as an unconscious ventricular fibrillation patient who requires emergency interventions until a higher level of care ambulance service arrives. The nursing population at CCI during this research period was predominantly female (91/124) with a broad range of education from Associate degrees in nursing to Master degrees in nursing. All participants were employed nurses at CCI. Refer to Table 1 for details of the entire nursing sample population of which 40 nursing participants were used for this study.

Table 1

California Correctional Institution Nursing Population Data for All Classifications

\begin{tabular}{lccccc} 
Classification & Age Range & Males & Females & Total & $\begin{array}{c}\text { Racial and Ethnic Groups } \\
\text { for All Classifications } \\
\text { CAUC: } 64\end{array}$ \\
\cline { 1 - 3 } SRNII & 39 to 66 & 3 & 8 & 11 & BLK: 29 \\
RN & 30 to 68 & 15 & 27 & 42 & Other: 13 \\
LVN & 29 to 66 & 12 & 39 & 51 & HISP: 18 \\
LPT & 25 to 64 & 3 & 17 & 20 & \\
Total: & 25 to 66 & 33 & 91 & 124 &
\end{tabular}

\section{Instrument}

There were no pre/post-test standardized tools located suitable for the DNP project. The research tool used was created for the DNP study, and will require 
further research standardization necessities. The data was collected over eight separate chosen days within October 2016 with five nurses in each simulation training group. The eight days were determined depending on nursing staff availability and management approval. There was one group of five nurses that participated on each day that one session was offered. The courses were given once per day for eight days, giving participants options for other sessions to participate if unable to make one particular course. The nurse staffing office was designated by the CCI management team to make the necessary accommodations for nurses to attend the simulation training.

The nurse staffing office provided coverage relief for the participating nurses that attended training. Recruitment of assistance utilized the office technician and management team to assist in the data collection process. Those supporting individuals were briefed and trained before the nursing staff simulation training sessions were scheduled. This occurred in one of the weekly supervising meetings to educate them regarding the plan and purpose of this study.

\section{Measures}

The studies primary (pre) and secondary (post) outcomes measured the scores of all participating nurses as one whole group. This was to indicate if there was a difference by using simulation approaches to learn. The pre/post-tests were the research tool for this study. It included non-standardized nursing associated close-ended questions with one open-ended question at the end. The close-ended questions were related to the patient care of a ventricular fibrillation EMR scenario. The open-ended question allowed participating nurses to elaborate on their thoughts and reflect on the simulation training experience. The pre/ post-test evolved around a simulation training script to evaluate correctional nursing 
performance (critical judgment, teamwork, nursing skills, and inter-relational effective communication) during a cardiac emergency situation.

Nurses used a simulation laboratory (lab) with similar equipment to the actual emergency clinic areas on each correctional yard. Each yard at CCI has its own emergency clinic due to the unique demographics of this institution. There are five yards total at CCI that hold different levels of inmate populations dependent on a point system and the incarcerated individuals convicted offense. The simulation lab had a crash cart, three-lead cardiac monitor, practice medications, and a high-fidelity manikin that were used during the given scenario for cardiac arrhythmia specifically ventricular fibrillation. The high-fidelity mannequin also had options for pre-recorded voice responses, changing pupil size kit, and interchangeable genitalia.

The nursing education department used a premium moulage kit that dressed the mannequin with cyanotic features for more real life enactment purposes. These are the measures that were used to prepare the simulation training for nurses to complete along with the pre and post-tests. A debrief period was initiated at the end of every completed group training session for purposes of making learning connections, and having an opportunity to give feedback. Nurses had the chance to explore the simulation lab and the mannequin to familiarize with the learning environment setting before beginning the training scenario. The nurse instructor also acclimated staff to all available equipment options that the simulation lab had to offer.

\section{Research Design}

This study was a quantitative quasi-experimental method. The pre and post test results were entered into the SPSS version 24 software program computing the 
data analysis through a paired sample t-test. Completion of pre and post-test questionnaires were scored and entered into a grade book for tracking and organizational purposes. These test scores were kept in a locked electronic computer to ensure secure keeping. Once the pre and post-tests had been examined for eligibility, the data was checked for errors and then entered into the software system for statistical analysis and reporting. The scores were compared with significant change findings. The results from SPSS determined significant statistical data relating to the nurses' abilities to improve performance during cardiac emergency response using high-fidelity simulation training approaches. 


\section{CHAPTER 4: RESULTS}

The paired sample statistics were completed by the same group of nursing individuals given the same test two times at different points during their highfidelity simulation training period. There were 40 nursing staff members that were given two mean scores. The paired sample test included two pairs of comparing scores of nursing staff before high-fidelity simulation training and after highfidelity simulation lab experience. The paired sample T-test covers the comparison of one time point series to the other time point. There is a trend that shows a significant difference in the pre and post-test scores. The nurses that completed simulation training have higher scores than the scores they achieved before receiving any simulation training. Mean differences between pre-test and post-test have indicating error bars to show the standard deviations (See Figure 1).

Out of the 40 individuals represented by $\mathrm{N}$, the results of the paired sample T-test was $t(39)=10.998, p<0.001, d=0.91643$. The findings of the Cohens $\mathrm{d}$ effect size is considered large as it is greater than 0.8 . Those in the post-test condition scored significantly higher $(\mathrm{M}=77.93, \mathrm{SD}=15.54)$ than those in the pretest condition ( $\mathrm{M}=62.01, \mathrm{SD}=19.21)$. The participants were able to improve scores after completing the high-fidelity simulation training relating to a cardiac emergency scenario. The significance of $\mathrm{p}<0.001$ is considered significant, and therefore the null hypothesis was rejected. This implies that there was a difference over the two-time points, and the intervention had an effect on the group. There was one group of individuals studied, and were expected to all vary in the same way. 


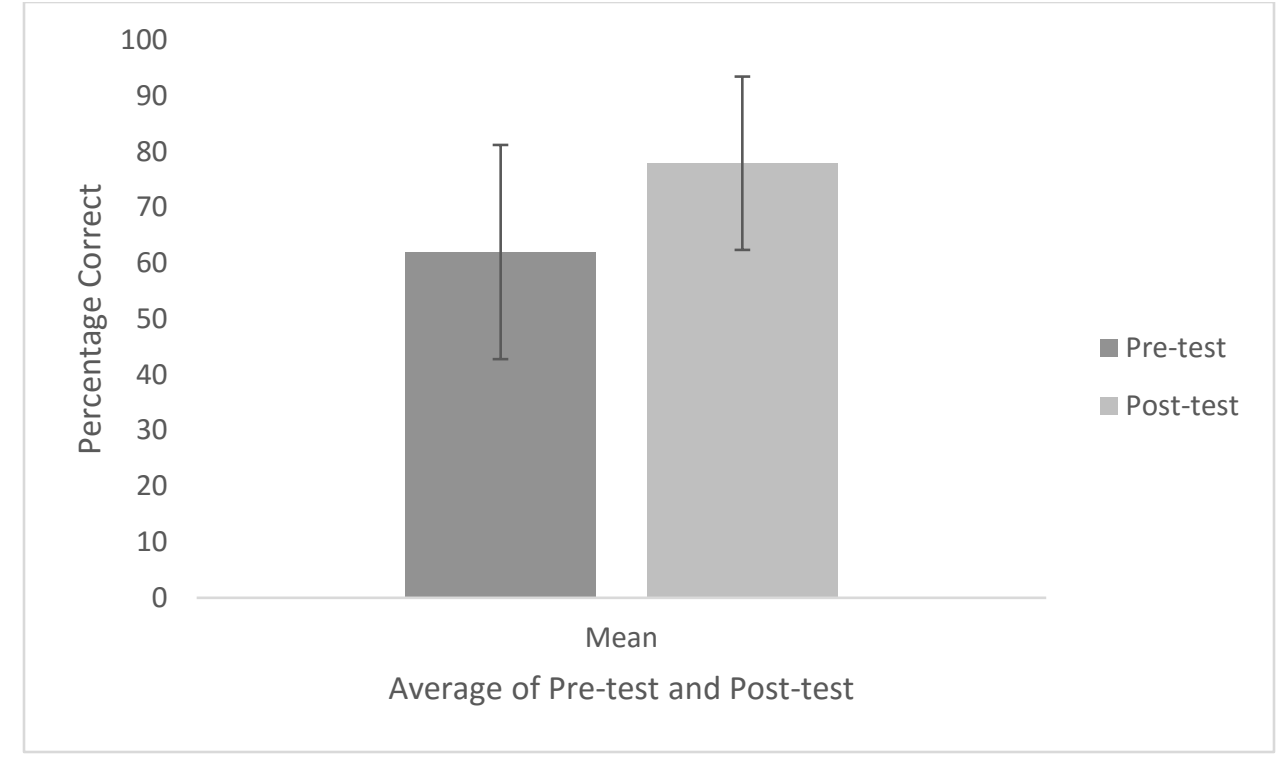

Figure 1. Pre and post-test scores for nurses who completed high-fidelity simulation training. 


\section{CHAPTER 5: DISCUSSION}

This study was conducted to explore correctional nurses using HFS training to improve cardiac emergency response. For this study, a quantitative analysis of 40 various nursing staff (RN, LPN, and LPT) participated in a pre and post-test that included ten cardiac emergency nursing multiple choice questions with one open ended question for feedback purposes on each exam. Prior to the pre-test, the nurses were given detailed instructions of the simulation training and requested to complete a consent form. Every participating nurse completed a consent form without difficulty and was able to ask any necessary questions relating to the simulation training expectations. The pre-tests were then given before the HFS training scenario and the post-tests were given after the completion of the training followed by the debriefing time period. All 40 nurses participated in the entire experience, and were eager to express their interest in using simulation training to learn.

As a result of the research analysis, a significance was found in post-test scores differing from the initial pre-test scores. The nursing staff demonstrated better understanding of cardiac emergency responses and showed post-test score improvements. The simulation lab allows correctional nurses to practice patient care away from the real-life patients in the clinical setting. In the past, CCI correctional nurses were expected to participate in quarterly drill scenarios directly in the clinic while continuing patient care duties simultaneously. That was the only scenario based trainings offered through nursing education at the time which proved lacking in learning outcomes. The quarterly drills have since been changed through the DNP nursing education curriculum development to reflect improved techniques of learning opportunities. 
One of the most positive outcomes of simulation training is that the students were able to build self-confidence in nursing skills and improve communication skills as a team. As Langdorf et al., (2014) discussed advanced cardiovascular life support (ACLS) deficits that were noted during simulation training, the CCI nurses experienced the same deficits in the simulation lab. The nurses were paired in random groups of five and were challenged to work as a team under specific given roles in a given simulated intense emergency situation. The learning experience allowed correctional nurses to practice patient care interventions based on CDCR policy and procedures without any risks to a live patient. The correctional nursing teams that participated in the educational opportunity were noted to improve overall performance of care during a cardiac emergency response. The overall performance was based on each nursing team's ability to integrate inter-relational effective communication, critical judgement, team work and nursing skills into the given ventricular fibrillation emergency scenario. HFS training adds the emotional component of the experience where the mannequin "speaks" to the student. Through the HFS experience, the learner is enabled test history-taking skills and building stronger therapeutic relationship between nurse and patient in crisis (Langdorf et al., 2014).

There were many positive aspects to simulation training for correctional nurses. However, some students did report during the debriefing session lack of HFS training experience and that the technology of equipment was new to them. Many nurses requested additional time to explore the simulation mannequin, and to engage in scenario-based education using HFS more often. Aside from HFS training, there are other elements of educational strategies necessary for grafting into the curriculum. These surrounding grafted aspects increase the learner's chance at re-enforced knowledge, retaining information, and translating those 
skills into clinical nursing practice. Since the nursing staff at CDCR-CCI has a diverse population, a well-rounded curriculum assists in accommodating different learning styles preferences. Some of these curriculum development learning resources used to enhance simulation training knowledge retention are webinar trainings, self-study assignments, classroom lectures, activities, and drills.

Other advantages of the simulation training were characterized by the Supervising Registered Nurse II (SRNII) being receptive to the simulation concept. The CCI nursing supervisors were able to improve their skill development and express interest in becoming better leaders. Some nurses reported feedback of negative experience during their simulation training experience. These lacking experiences included the location of the simulation lab being centralized in one location instead of the convenience of equipment mobility to all yards. Nurses verbalized that at times, the automated external defibrillator (AED) with a built in rhythmic structure was more distracting then helpful. It was also discussed during debrief of chaos and synchronizing coordination nursing team difficulties. This hindered nurses from the ability to stay completely focused during the emergency scenario. Similar to first exposure experiences of psychologically intense simulation environments causing inability to pay attention to what their peers were doing (Suk Jeong, Sang Suk, \& Young-Mi, 2015).

In order to increase effectiveness for correctional nurses to improve emergency medical response performance, simulation training will be integrated into the teaching curriculum amongst other grafted educational strategies. The feedback responses from nursing learners will be considered when creating future scenario-based simulation trainings. The mobility of nursing education equipment has been achieved by purchasing pieced parts for easier transportation instead of the entire Mega Code Kelly mannequin. This equipment was purchased for 
correctional nurses to have an opportunity at practicing short sections of drills from the simulation experience in the lab environment. The innovation and technology of simulation training and short drills are important training tools to prepare correctional nurses for the real-life emergency situations. The concept is to facilitate spontaneous cognitive thought processes, improve critical judgement, communication effectiveness, and increase nursing skill confidence. By collectively improving these identified lacking areas in the Cycle 4 OIG medical inspection report, correctional nurses will become more confident and efficient in emergency response patient care.

Finally, the debriefing process from the simulation training included all participating correctional nurses. This is a process where nurses have the opportunity to gain reflective insight from an experience to strengthen their learning senses by peer feedback. That debriefing process is known as one of the most imperative components to learn from simulation trainings (Reilly \& Spratt, 2007). The nurses were observed engaging in meaningful conversations and learning from each other as the debrief process progressed. Quantitative analysis showed the significant difference in pre and post-test scores linking the effectiveness of HFS education. The limitation of this study was that the number of participants was small, and conducted at only one CDCR correctional facility. Further studies are needed to verify the effectiveness of HFS training between one facility and multiple facilities with increased amounts of participants. There is also needs for further research in standardization of the DNP research pre and post-test tool. 


\section{Conclusion}

This first simulation lab at CCI was created through the careful planning and nursing considerations by the nursing education department. Correctional nurses who participated in the simulation lab HFS experience were amongst the first in the state to use such innovative equipment. The management team at CCI was greatly impressed by the DNP research and associated curriculum that led to its feature article debut on the CDCR intranet share website called Lifeline. Correctional medical staff of various disciplines from 35 CDCR institutions had access to this feature article, and were eager to share their positive feedback and thoughts. The future of simulation training at CDCR has begun, and through this DNP research has paved the way for future advancement to the way correctional nurses receive continuous best-practice education. There is room for innovation, growth, and new outlook in educational leadership inspiring correctional nurses to thrive and continue improving quality patient care as a whole. 


\section{REFERENCES}

Anand, P. (2012). California's department of corrections: Shifting prisoners and costs to counties. Retrieved from http://cacs.org/research/californiasdepartment-of-corrections-shifting-prisoners-and-costs-to-counties/

Aqel, A. A., \& Ahmad, M. M. (2014). High-fidelity simulation effects on CPR knowledge, skills, acquisition, and retention in nursing students. Worldviews on Evidence-Based Nursing, 11(6), 394-400. doi:10.1111/wvn.12063.

Background Class Action Lawsuits (2012). Retrieved from http://www.cdcr.ca.gov/2012plan/docs/Fact-Sheet-Class-ActionLawsuits.pdf

Barton, R. A. (2016). California Correctional Institution medical inspection results cycle 4, 1-100. Retrieved from http://www.oig.ca.gov/media/reports/MIU/CYCLE4/CCI_Medical_Inspectio n Report_Cycle_4.pdf

Benner, P. (1982). From novice to expert. American Journal of Nursing, 82(3), 402-407. doi:10.1097/00000446-198282030-00004.

Benner, P. (2011). Formation in professional education: An examination of the relationship between theories of meaning and theories of the self. Journal of Medicine and Philosophy, 36(4), 342-353. doi:10.1093/jmp/jhr030. 
Buell, J. (2010). Lean Six Sigma and patient safety: A recipe for success. Healthcare Executive, 25(2), 26-32.

California Department of Corrections and Rehabilitations (1980).California prisoners. Retrieved from http://www.cdcr.ca.gov/reports_research/offender_ information_services_branch/Annual/CalPris/CALPRISd1980.pdf

California Department of Corrections and Rehabilitations (2015). Visitation general information. Retrieved from http://www.cdcr.ca.gov/Visitors/General_Information.html

Cazzell, M., \& Anderson, M. (2016). The impact of critical thinking on clinical judgment during simulation with senior nursing students. Nursing Education Perspectives, 37(2), 83-90. doi:10.5480/15-1553.

CDCR Budget Information. (2016). Retrieved from http://www.cdcr.ca.gov/Budget.

Clayton, E. (2015). Correctional Nursing. Arizona Nurse, 68(1), 12.

Curl, E. D., Smith, S., Chisholm, L. A., McGee, L. A., \& Das, K. (2016). Effectiveness of integrated simulation and clinical experiences compared to traditional clinical experiences for nursing students. Nursing Education Perspectives, 37(2), 72-77. doi:10.5480/15-1647.

Díaz, D. A., Panosky, D. M., \& Shelton, D. (2014). Simulation: Introduction to correctional nursing in a prison setting. Journal of Correctional Health Care, 20(3), 240-248. doi:10.1177/1078345814532324. 
Forneris, S. G., Neal, D.O., Tiffany, J., Kuehn, M. B., Meyer, H. M., Blazovich, L. M., Holland, A. E., Smerillo, M. (2015). Enhancing clinical reasoning through simulation debriefing: A multi-site study. Nursing Education Perspectives, 36(5), 304-310. doi:10.5480/15-1672.

Garbee, D. D., Paige, J., Barrier, K., Kozmenko, V., Kozmenko, L., Zamjahn, J., \& Cefalu, J. (2013). Interprofessional teamwork among students in simulated codes: A quasi-experimental study. Nursing Education Perspectives, 34(5), 339-344.

Harris, M. A., Pittiglio, L., Newton, S. E., \& Moore, G. (2014). Using simulation to improve the medication administration skills of undergraduate nursing students. Nursing Education Perspectives, 35(1), 26-29. doi:10.5480/11552.1.

Langdorf, M. I., Strom, S. L., Yang, L., Canales, C., Anderson, C. L., Amin, A., \& Lotfipour, S. (2014). High-fidelity simulation enhances ACLS training. Teaching \& Learning in Medicine, 26(3), 266-273.

Liaw, S. Y., Palham, S., Chan, S. W., Wong, L. F., \& Lim, F. P. (2015). Using simulation learning through academic-practice partnership to promote transition to clinical practice: A qualitative evaluation. Journal of Advanced Nursing, 71(5), 1044-1054. doi:10.1111/jan.12585. 
Los Angeles Times (2015). California regains control over healthcare at Folsom prison. Retrieved from http://www.latimes.com/local/political/la-me-ffcalifornia-regains-control-healthcare-folsom-prison-20150713-story.html Porter-O'Grady, T., \& Malloch, K. (2011). Quantum leadership: Advancing innovation, transforming health care (3rd Edition). Sudbury, MA: Jones \& Bartlett Learning.

Reilly, A. \& Spratt, C. (2007). The perceptions of undergraduate student nurses of high-fidelity simulation-based learning: A case report from the University of Tasmania. Nurse Education Today, 27, 542-550.

Rold, W. J., (2008). Thirty years after Estelle v. Gamble: A legal retrospective. Journal of Correctional Health Care. doi:10.1177/1078345807309616.

Simon, R., Raemer D. B., \& Rudolph, J. W. (2009). Debriefing assessment for simulation in healthcare. Boston, MA: Center for Medical Simulation.

Simmons, S. J. (1990). The health-promoting self-care system model: Directions for nursing research and practice. Journal of Advanced Nursing, 15(10), 1162-1166. doi:10.1111/j.1365-2648.1990.tb01708.x.

Stuenkel, K., \& Faulkner, T. (2009). A community hospital's journey into Lean Six Sigma. Frontiers of Health Services Management, 26(1), 5-13.

Suk Jeong, L., Sang Suk, K., \& Young-Mi, P. (2015). First experiences of highfidelity simulation training in junior nursing students in Korea. Japan Journal of Nursing Science, 12(3), 222-231. 
APPENDICES 
APPENDIX A: ORAL PRESENTATION POWERPOINT 


\section{Curriculum Development of California} Correctional Institution (CCI) Nursing Staff Performance During Simulation Training Related To Cardiac Emergency Response.

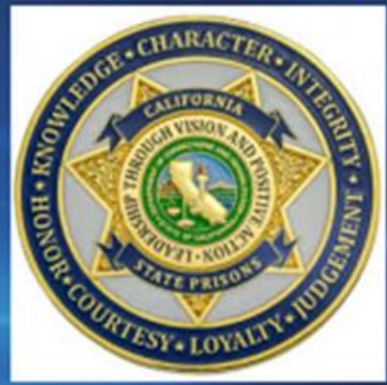

Dina Wang, DNP(c), RN, CCHP

California State University Northern California Consortium, Doctor of Nursing Practice Program

\section{Acknowledgements}

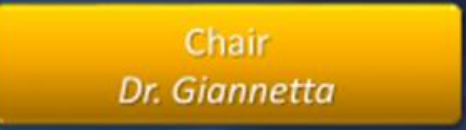

Mentor

Mariana Teel

Advisor

Dr. Ortiz

Committee

Rhonda Litt

Mariana Teel

Family

Parents and

Friends
California Department of Corrections and

Rehabilitations (CDCR)

-Committee for the Protection of Human

Subjects (CPHS)

-California Correctional Institution (CCI)

Nursing Staff Participants 


\section{Background}

- $\mathrm{CCl}$ is one of 35 institutions in California Department of Corrections and Rehab.

- Office of Inspectors General (OIG) Medical Report (2016)

- Nursing Education Department

- Annual Nurse Training

- Classroom Teaching Modules

- Theory and Clinical Practice

- Nursing Skills

\section{Introduction}

- High-Fidelity Simulation (HFS) Training for Correctional Nurses

- Simulation Lab

- Education curriculum development

- Performance enhancement focus

1. Critical Thinking

2. Communication

3. Nursing Skills

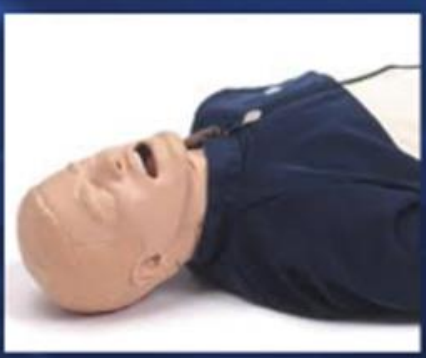




\section{Problem and/or Problem Statement}

- Currently, there is no standardized emergency medical response training for all correctional institutions.

- Minimal amounts of research has been conducted with correctional nurses and performance improvement measures.

- OIG Cycle 4 medical inspection reported an "inadequate" score for $\mathrm{CCl}$ emergency medical services.

- 63 Urgent/Emergent events were reviewed with 52 deficiencies in the area of nursing care.

\section{Purpose of the project}

- Initiated improvement plan

- Improve cardiac emergency

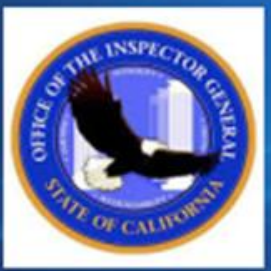
response deficiencies as indicated by OIG

- $\mathrm{CCl}$ to continue as a leading role model institution

- Develop mock code scenarios for highfidelity simulation training integrated into selected $\mathrm{CCl}$ educational training curriculum 


\section{Theoretical Framework}

- Patricia Benner

- Novice to expert nursing concept.

- Novice Nurse

- Advanced Beginner

- Competent

• Proficient

- Expert

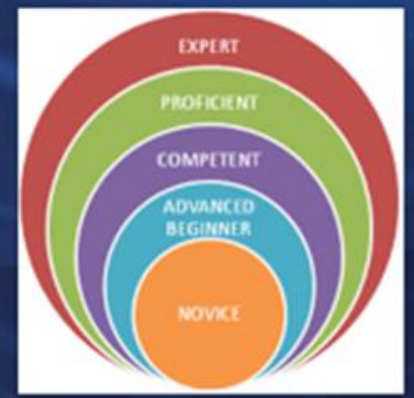

\section{Review of the literature}

- Cazzell, M., \& Anderson, M. (2016).

- Impact of critical thinking (CT) and judgment (CJ) during sim training with nursing students

- Testing, Rubric, and Videotaped session used for scoring.

- Innovative teaching strategies are needed for $\mathrm{CT}$ and $\mathrm{CJ}$.

- Díaz, D. A., Panosky, D. M., \& Shelton, D. (2014).

- Introduction to sim training in correctional setting

- High fidelity manikin simulator

- Group actors, scenario-based education with debrief

- Forneris et al. (2015)

- Simulation debriefing with nursing students

- Critical thinking skills development

- Pre/post test measures used 


\section{Methods}

- Quantitative, quasi-experimental method

- One local institutional facility

- A pre/post-test was used to evaluate nursing learned scores.

- The scenario: 10-15 minutes

- Group's teamwork performance utilized

- Following 20-30 minute debriefing session

\section{Data Analysis Bar Chart}

100

90

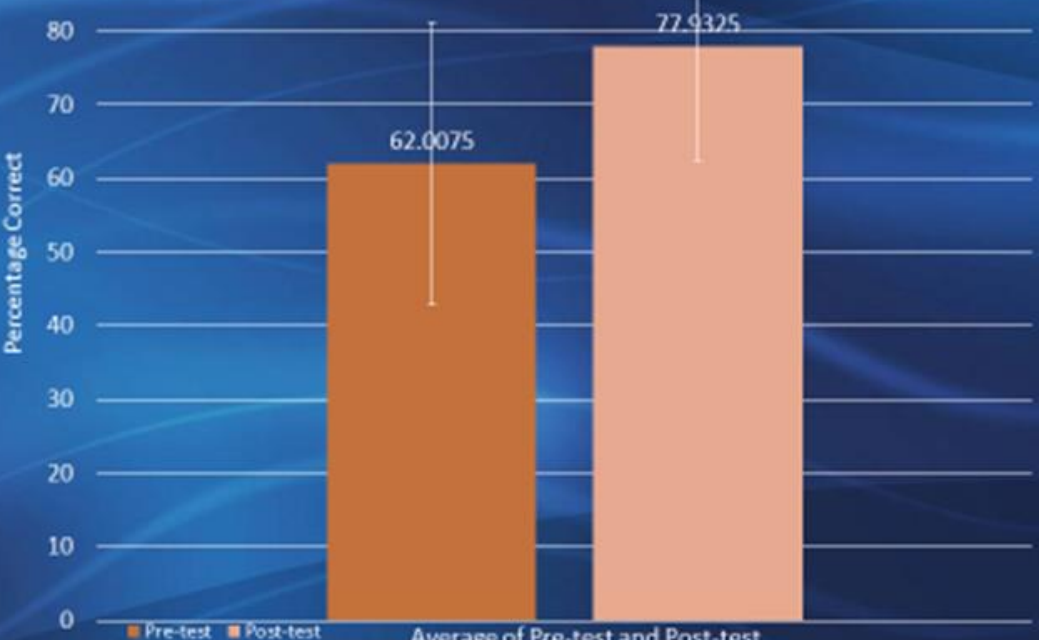




\section{Discussion or Outcomes}

- 40 staff members participated (RN, LPN, LPT)

- Nurses were eager to express their sim lab experience.

- Post-test score showed significant score improvements.

- One positive outcomes was nurses built self-confidence in nursing skills

- Another positive outcome was improving communication skills as a team.

\section{Conclusions}

- First simulation lab created at $\mathrm{CCl}$

- Lifeline

- Innovation, growth, and new outlook in educational leadership inspiring correctional nurses to thrive.

- Improve quality patient care as a whole

- Contribute to standardization concept of nursing education.

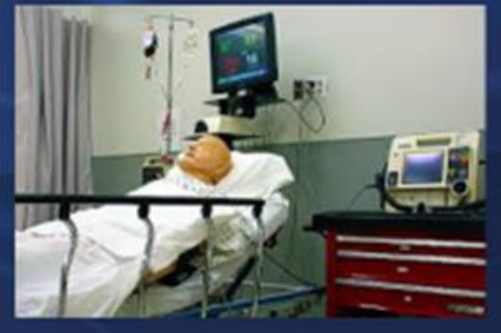




\section{Limitations}

- Additional time to explore the simulation mannequin

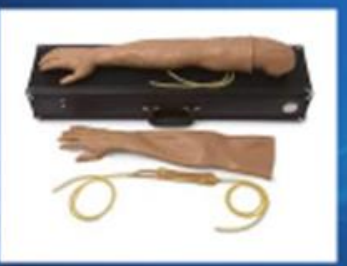

- Engage in scenario-based education using HFS more often.

- Automated external defibrillator (AED) with a built in rhythmic structuredistracting

- Centralized simulation lab

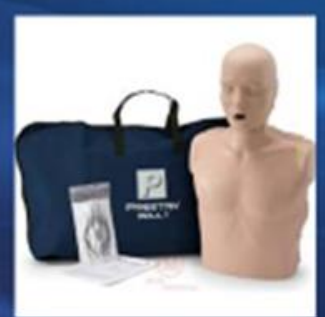

\section{What is next?}

- The future of simulation training at CDCR has begun, and through this DNP research has paved the way for future advancement to the way correctional nurses receive continuous best-practice education.

- Continued curriculum development includes:

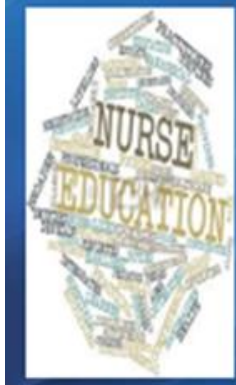

- Interactive Web Modules

- Pieced simulation equipment for drills

- Weekly skills lab

- High-fidelity simulation lab scenario training 


\section{References}

CCPOA video: One of the bloodiest riots in California's penal history.

\section{References}

Barton, R. A. (2016). California Correctional Institution Medical Inspection Results Cycle 4, 1-100. Retrieved July 1, 2016, from http://www.oig.ca.gov/media/reports/MIU/CYCLE4/CCI_Medica I_Inspection_Report_Cycle_4.pdf

Benner, P. (1982). From novice to expert. American Journal of Nursing, 82(3), 402-407.

Benner, P. (2011). Formation in professional education: An examination of the relationship between theories of meaning and theories of the self. Journal of Medicine and Philosophy, 36(4), 342-353. doi:10.1093/jmp/jhr030.

Cazzell, M., \& Anderson, M. (2016). The impact of critical thinking on clinical judgment during simulation with senior nursing students. Nursing Education Perspectives, 37(2), 83-90. CDCR Budget Information. (2016, January). Retrieved May 3, 2016, from http://www.cdcr.ca.gov/Budget. 


\section{References}

Curl, E. D., Smith, S., Chisholm, L. A., McGee, L. A., \& Das, K. (2016). Effectiveness of integrated simulation and clinical experiences compared to traditional clinical experiences for nursing students. Nursing Education Perspectives, 37(2), 72-77. doi: $10.5480 / 15-1647$.

Díaz, D. A., Panosky, D. M., \& Shelton, D. (2014). Simulation: introduction to correctional nursing in a prison setting. Journal of Correctional Health Care, 20(3), 240-248.

Forneris, S. G., Neal, D.O., Tiffany, J., Kuehn, M. B., Meyer, H. M., Blazovich, L. M., Holland, A. E., Smerillo, M. (2015). Enhancing clinical reasoning through simulation debriefing: A multisite study. Nursing Education Perspectives, 36(5), 304-310. doi:10.5480/15-1672.

\section{References}

Garbee, D. D., Paige, J., Barrier, K., Kozmenko, V., Kozmenko, L., Zamjahn, J., \& ... Cefalu, J. (2013). Interprofessional teamwork among students in simulated codes: A quasi-experimental study. Nursing Education Perspectives, 34(5), 339-344.

Harris, M. A., Pittiglio, L., Newton, S. E., \& Moore, G. (2014). Using simulation to improve the medication administration skills of undergraduate nursing students. Nursing Education Perspectives, 35(1), 26-29. doi:10.5480/11-552.1

Langdorf, M. I., Strom, S. L., Yang, L., Canales, C., Anderson, C. L., Amin, A., \& Lotfipour, S. (2014). High-fidelity simulation enhances ACLS training. Teaching \& Learning In Medicine, 26(3), 266-273.

Liaw, S. Y., Palham, S., Chan, S. W., Wong, L. F., \& Lim, F. P. (2015). Using simulation learning through academic-practice partnership to promote transition to clinical practice: a qualitative evaluation. Journal of Advanced Nursing, 71(5), 1044-1054. doi:10.1111/jan.12585. 


\section{References}

Reilly, A. \& Spratt, C. (2007). The perceptions of undergraduate student nurses of high-fidelity simulation-based learning: A case report from the University of Tasmania. Nurse Education Today, 27, 542-550.

Rold, W. J., (2008). Thirty years after Estelle v. Gamble: A legal retrospective. Journal of Correctional Health Care. DOI: $10.1177 / 1078345807309616$

Simon, R., Raemer D. B., \& Rudolph, J. W. (2009). Debriefing assessment for simulation in healthcare. Boston, MA: Center for Medical Simulation.

Simmons, S. J. (1990). The health-promoting self-care system model: Directions for nursing research and practice. Journal of Advanced Nursing, 15(10), 1162-1166.

Suk Jeong, L., Sang Suk, K., \& Young-Mi, P. (2015). First experiences of high-fidelity simulation training in junior nursing students in Korea. Japan Journal of Nursing Science, 12(3), 222-231.

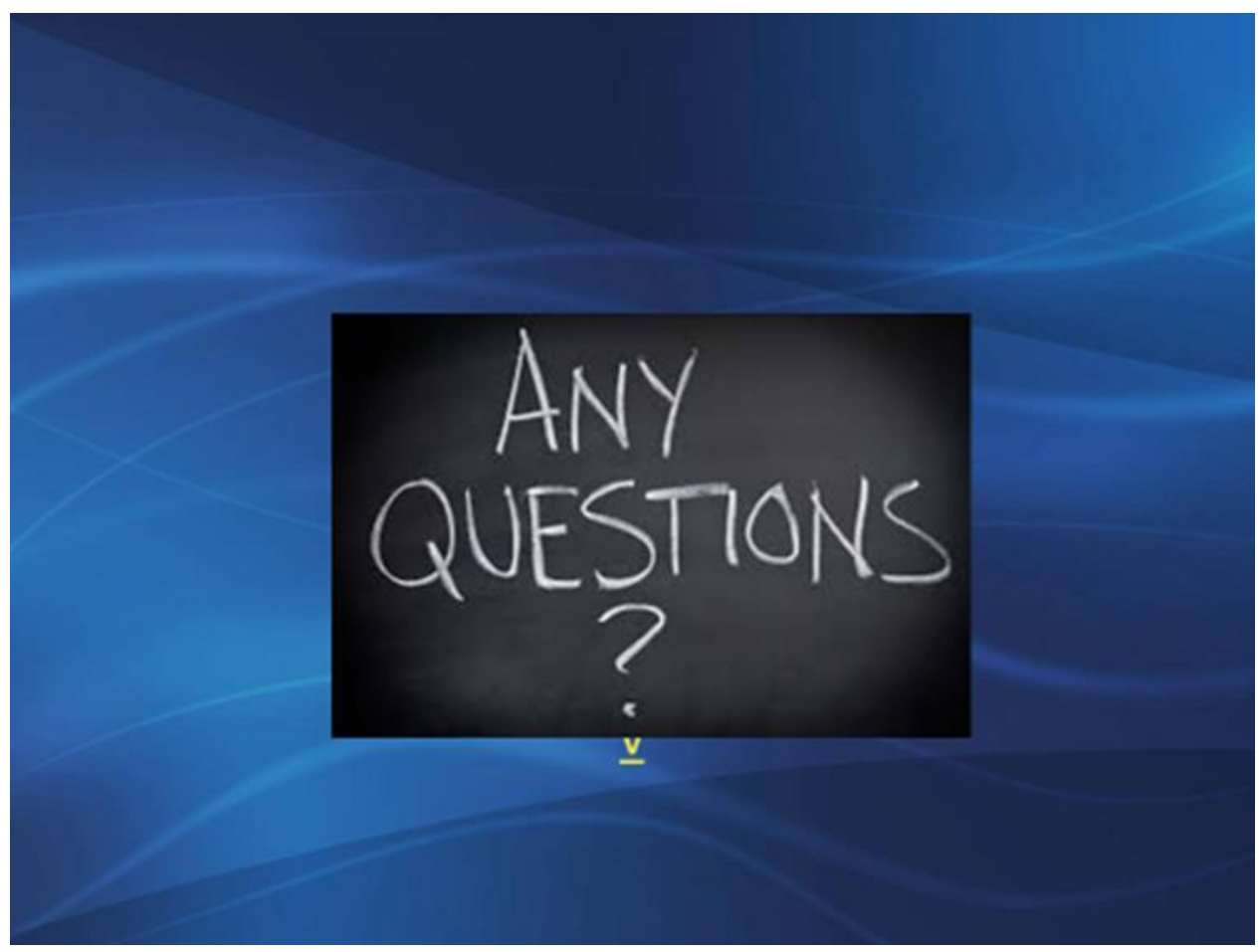




\section{Thank You}

Phone: 661-916-5503

Email: Dina.Wang@cdcr.ca.gov 
APPENDIX B: LIFELINE ARTICLE 


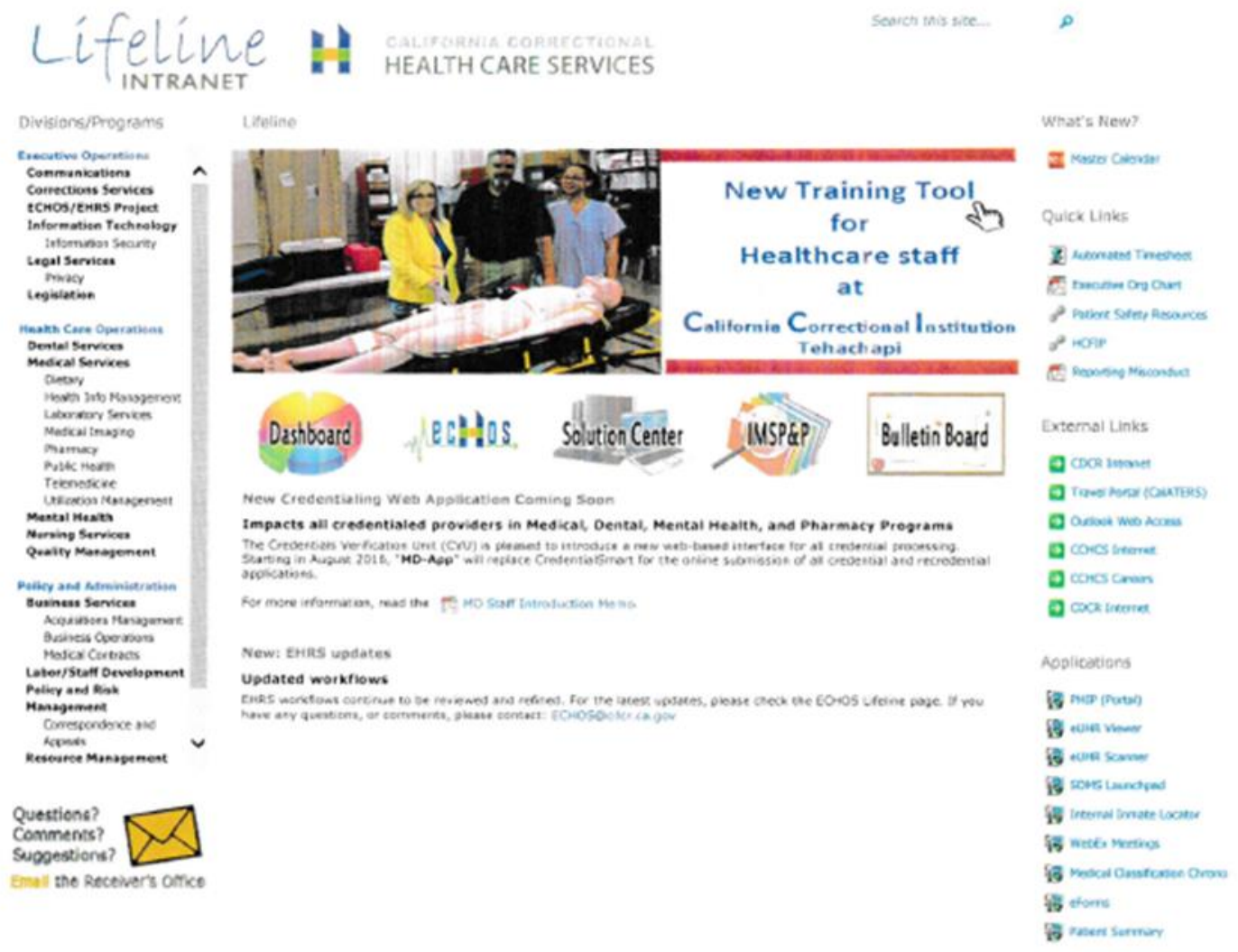




\section{New Training Tool for Healthcare Staff at California Correctional Institution Tehachapi}

The Nursing Instructor's office at the California Correctional Institution (CCI) in Tehachapi has an advanced training tool - a mannequin-based emergency response patient simulator. The mannequin simulates breathing patterns that change as the level of distress change. This exciting new training tool will assist healthcare staff in maintaining, as well as improving, their emergency response skills.

Pictures left to right:

Kandiss Alonzo, SRN II (A); Dina Wang, NI; Charles Reinhold, DON (A)

Dina Wang Nl: Charles Reinhold, DON (A); Dana Buford, CNE (A)

Kandiss Alonzo, SRN II (A); Dina Wang, NI, Charles Reinhold, DON (A)

Note: Dina Wang. NI, is working towards a PhD in Nursing and is conducting research on emergency response skills for the institution in conjunction with fulflling her doctorate requirements.

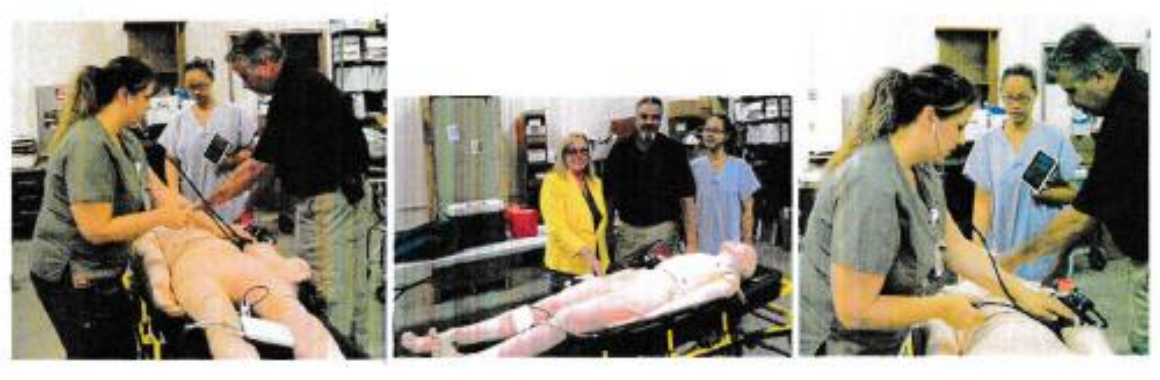


APPENDIX C: CDCR RESEARCH APPROVAL LETTER 
STATE OF CALIFORAIA - DEPARTMENT OF CORRECTIONS AND REMABIITATION

EDMUND G. BROWN JR., GOVERNOR

OFFICE OF RESEARCH

P.O. Box 942883

Sacramento, CA 94283-0001

November 17, 2016

Dina Wang

Correctional Nurse Instructor

California Correctional Institute

$4336146^{\text {th }} \mathrm{St}$.

W. Lancaster, CA 93536

Dear Ms. Wang:

The California Department of Corrections and Rehabilitation (CDCR), Research Advisory Committee (RAC), has reviewed your research proposal, "Curriculum Development of California Correctional Institution (CCl) Nursing Staff Performance During Simulation Training Related to Cardiac Emergency Response." This letter certifies that the RAC has approved your research proposal. Please keep this approval letter for your records. The expiration of the approval will coincide with your expiration date from the Fresno State University, Department of Nursing, Institutional Review Board on September 13, 2017.

As the Principal Investigator, it is your responsibility to comply with Department regulations and State law. Specifically, the Department Operations Manual regulations, Chapter 1, Article 19, Section 14020.7, which requires that all research activities and proposals involving departmental facilities, employees, and inmates are coordinated through the Office of Research.

If you have any questions regarding this letter, please contact Ashley Gabbard, Section Chief, Research and Evaluation Branch at (916) 324-8890.

Sincerely,

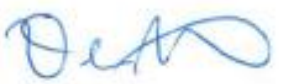

DENISE M. ALLEN

Chief

Office of Research

cc: Ashley Gabbard, Section Chief 
APPENDIX D: CPHS RESEARCH APPROVAL LETTER 
Wang, Dina

California Department of Corrections and Rehabilitation

4336146 th St. W.

Lancaster , CA 93536

Project Title: Curriculum Development of California Correctional Institution Nurse Staff Perforrnance During Simulation Training Related to Cardiac Emergency Response

Project Number: $16-09-2723$

Dear Ms. Wang,

The Committee for the Protection of Human Subjects (CPHS) has Approved the above Request for Determination. It is Not Research and/or Exempt from CPHS review and does not require CPHS approval to be conducted. This decision is issued under CPHS' Federalwide Assurance \#00000681 with the Office of Human Research Protections (OHRP).

If the parameters of your project change, or are reasonably expected to change, so that the project may no longer meet the federal requirements for not being research or for being exempt research, you must either:

-Submit another Request for CPHS Determination of Not Research or Exempt Research -Submit a New project to CPHS for approval.

The Request or New project must describe the changes occurring or expected to occur in your project. If such a Request or New project is submitted, you must not implement any changes until you receive written confirmation from CPHS that your project either does not constitute research, is exempt from CPHS review, or is approved research.

If you have any questions, you may call our office at (916) 326-3660 or email us at cphs-mail@oshpd.ca.gov.

Sincerely, 
STATE OF CALIFORNIA - HEALTH AND HUMAN SERVICES AGENCY EDMUND G. BROWN JR., Governor COMMITTEE FOR THE PROTECTION OF HUMAN SUBJECTS 400 R Street, Suite 359

Sacramento, California 95811-6213

(916) 326-3660 FAX (916) 322-2512

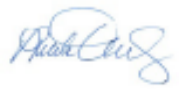

Lucila Martinez

CPHS Administrator

(916) 326-3661

lucila.martinez@oshpd.ca.gov 
APPENDIX E: HIGH FIDELITY SIMULATION SCENARIO SCRIPT 
CARDIAC EMERGENCY RESPONSE CASE SCENARIO

\section{Mock Code Scenario}

Program/Curriculum Specific Objectives. This scenario is intended to:

- Offer opportunity to practice emergency response using high fidelity simulation training

- Improve nursing skills and learner confidence

- Improve nursing and custody team work and communication

- Improve standards in quality patient care

\section{Measurable Objectives}

1. The nurse learner will demonstrate proper cardiovascular and pulmonary assessment.

2. The nurse learner will recognize assessment findings irregular to patient.

3. The nurse learner will provide appropriate interventions to patient emergency situation.

4. The nurse learner will take leadership and collaborate with custody demonstrating effective CPR/ACLS as appropriate. ACLS will be performed with a MD at bedside per CCHCS policy and procedures.

5. Learner will communicate effectively and assume health care roles cohesively caring for patient.

Authors: California Department of Corrections and Rehabilitations, Wang, D. Nurse Instructor, California Correctional Institution.

Will There Be Any Pre-Simulation Lecture? \ Yes. At facilitator's discretion, lecture will include concepts of high-fidelity simulation training and brief review of cardiac emergency medical care. Nursing staff will also engage in a pre-test activity prior to actual simulation training opportunity.

Duration: $20-30$ minutes.

Expected Scenario Time 10-15 minutes per scenario

Expected Debrief Time 20-30 minutes per scenario

Report and Information Provided To Participants Prior To Simulation

Scenario 1

Situation: Inmate Kelly Simman was brought to the clinic with increasing symptoms of SOB, dizziness, rapid heartbeat, and chest pain. He was given $15 \mathrm{~L}$ non-rebreather mask oxygen delivery 


\section{CARDIAC EMERGENCY RESPONSE CASE SCENARIO}

during transport from the housing unit and transported via gurney to the TTA clinic. Once in the TTA clinic, patient becomes unconscious.

Background: Patient has a history of coronary artery disease and hypertension $\mathrm{x} 10$ years and had an $\mathrm{MI}$ in 2011. He previously smoked 1 pack of cigarettes per day for 20 years, but quit smoking when he came into the prison setting in 2010. The patient's current medications are Lasix, Hydrochlorothiazide, Digoxin and Aspirin.

Assessment: Current vital signs are: BP 94/48, Pulse 126, RR 32, T 98.6F, SPO2 92\% @ 15L/min via NR prior to becoming unconscious.

Cardiac Rhythm: Ventricular Fibrillation

Abdominal Sounds: Hypoactive. Pt. has increased work of breathing.

Recommendation: Call for a Code 3 Ambulance for higher level of care. Complete CPR/ACLS and permitted medical interventions per CCHCS protocol interventions until EMS arrives.

Patient Information

Patient Name: Kelly Simman $\quad$ Gender: Male Weight: 198 lbs.

Age:71

Birth date:, 01/31/1945 Height: 5'10"

\ID CDC\# MC1234 Cell: H2-105-16L

Hx. Present Illness: Mr. Simman is a 71 year old gentleman residing in the prison setting since 2010 . He has a history of coronary artery disease and hypertension x 10 years and had an MI in 2011. Patient lives in a cell and independent with ADL's. He takes his medication prescriptions but misses occasional doses. For the last day, he has been complaining of increased fatigue and shortness of breath.

Social History: Unknown as patient is currently incarcerated. He does have family listed on his emergency contacts and records show that he attends occasional visitation hours on the weekends.

\section{Religion: N/A}

Allergies: NKDA

Immunizations: Up-to Date Attending Physician: Dr. Savalife

Past medical history: Pt is a 71 year old gentleman with past history of coronary artery disease and hypertension x 10 years. He had an MI in 2011. Current medications are Lasix, Hydrochlorothiazide, Digoxin and Aspirin.

Moulage: Male manikin. Apply thin layer of modeling wax on lips and face and apply makeup to have pt appear pale and cyanotic (blue shadow to lips, eyelids, fingers and toes).

\section{Assignment Of Roles}

$\triangle$ Clinical Nurse Instructor

$\triangle$ Primary TTA Nurse

\Secondary Registered Nurse/ SRN 
CARDIAC EMERGENCY RESPONSE CASE SCENARIO

$\bigotimes$ Scribe $\quad$ Licensed Vocational Nurse or Psychiatric Technician

\Secondary Licensed Vocational Nurse or Psychiatric Technician

$\triangle$ Observers

Important Information Related To Potential Roles:

Scenario: For Senior Nursing Staff Participants: Primary Registered Nurse, Secondary Registered Nurse/SRNII, LVN,

Secondary LVN (Optional: Physician, Custody)

\section{SIM Setup}

Moulage Manikin should be pale, cyanotic and having increased respirations.

Mannequin Laerdal MegaCode Kelley with Advanced SimPad

IV site: $\quad$ Site: Right Antecubital Gauge $18 \mathrm{G}$ for scenario.

Blood Pressure Site: Left Antecubital (Manual)

CPR: Left chest with spring coil 
CARDIAC EMERGENCY RESPONSE CASE SCENARIO

\begin{tabular}{|c|c|}
\hline Fidelity : Preferably high fidelity manikin or mid-f & lity/standard patient hybrid. \\
\hline 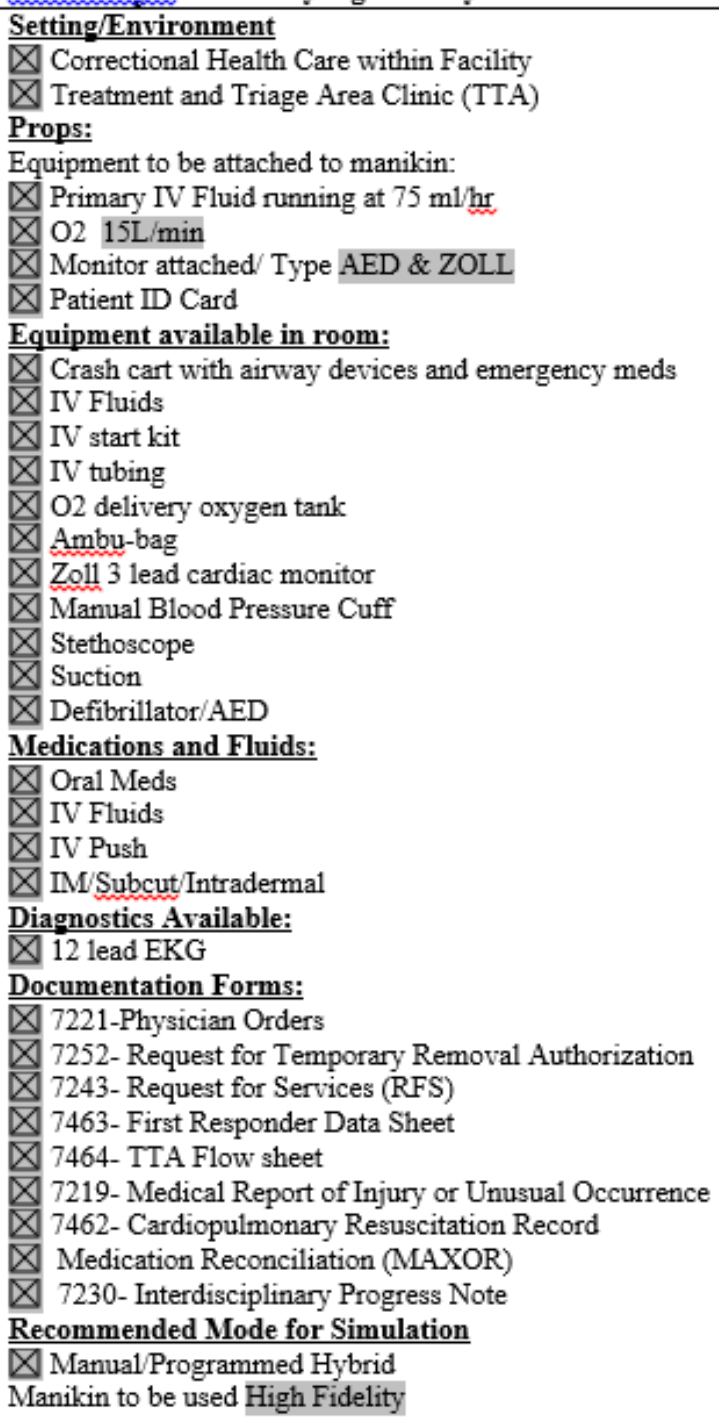 & $\begin{array}{l}\text { Physician Orders: } \\
\text { Scenario: (TTA Clinic Setting) } \\
\text { Full Code } \\
\text { Vital signs per policy } \\
\text { IV access } \\
\text { ACLS interventions } \\
\text { O2 Saturation above } 92 \% \text { via NR @ } 15 \mathrm{~L} \\
\text { Glucometer for FSBS } \\
\text { Dextrose } 501 \text { ampule IV push } \\
\text { Higher level of care transfer } \\
\text { Code } 3 \text { Ambulance requested } \\
\text { Assess cardiac rhythm } \\
\text { Use of Oral or Nasopharyngeal airway } \\
\text { MD discretion to intubate }\end{array}$ \\
\hline
\end{tabular}




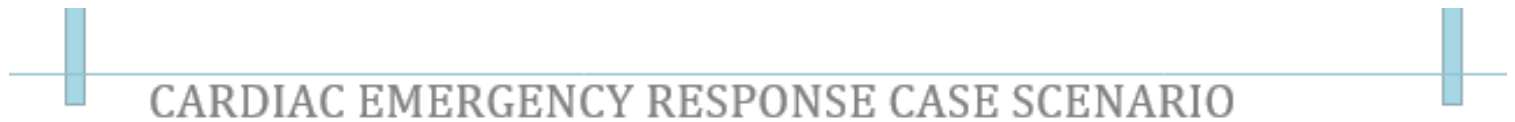

\section{Scenario Progression Outline}

平

\begin{tabular}{|c|c|c|c|c|}
\hline $\begin{array}{l}\text { Initial Amount } \\
\text { Time in Initial } \\
\text { Stage- } 3 \text { mins }\end{array}$ & $\begin{array}{l}\text { Verbalization } \\
\text { (Pt/Manikin } \\
\text { Cues) }\end{array}$ & $\begin{array}{l}\text { Expected } \\
\text { Interventions }\end{array}$ & $\begin{array}{l}\text { Alternate or Incorrect } \\
\text { Treatment Choice } \\
\text { That Will Affect } \\
\text { Outcome }\end{array}$ & $\begin{array}{l}\text { Confederate } \\
\text { Actions/Additional } \\
\text { Role Player Cues }\end{array}$ \\
\hline $\begin{array}{l}\text { Vital Signs } \\
\text { BP 94/48, Pulse } \\
126, \mathrm{RR} 32, \mathrm{~T} \\
98.6 \mathrm{~F}, \mathrm{SPO} 292 \% \\
\text { @ } 15 \mathrm{~L} / \text { min via NR } \\
\text { prior to becoming } \\
\text { unconscious. } \\
\text { Cardiac Rhythm: } \\
\text { Ventricular } \\
\text { Fibrillation } \\
\text { Breath Sounds: } \\
\text { Diminished, } \\
\text { Shallow, Rapid } \\
\text { Abdominal Sounds: } \\
\text { Hypoactive } \\
\text { Other Symptoms: } \\
\text { Anxious, Lips } \\
\text { becoming cyanotic } \\
\text { Trending VS: O2 } \\
\text { sats } \downarrow, \text { HR } \uparrow, R R \uparrow, \\
\text { BP } \downarrow, T \uparrow \\
\text { Eventually } \\
\text { Patient becomes } \\
\text { unresponsive and } \\
\text { code is called. } \\
\text { Blood glucose is } \\
\text { found to be } 58 \\
\text { during code. }\end{array}$ & $\begin{array}{l}\text { Pt has been } \\
\text { brought to } \\
\text { TTA clinic } \\
\text { from the } \\
\text { housing unit } \\
\text { with complaint } \\
\text { of SOB, } \\
\text { dizziness, } \\
\text { rapid } \\
\text { heartbeat, and } \\
\text { chest pains. } \\
\text { Patient } \\
\text { verbalizes } \\
\text { "I'm not } \\
\text { feeling so } \\
\text { well", "my } \\
\text { chest hurts and } \\
\text { I can't } \\
\text { breathe" Pt } \\
\text { shows } \\
\text { increased work } \\
\text { of breathing. } \\
\text { Pt becomes } \\
\text { increasingly } \\
\text { confused and } \\
\text { anxious until } \\
\text { finally is non- } \\
\text { responsive }\end{array}$ & $\begin{array}{l}\text { Assess patient } \\
\text { thoroughly. Checks } \\
\text { for and recognizes } \\
\text { rhythm changes, } \\
\text { increase worsening } \\
\text { work of breathing, } \\
\text { and vital sign } \\
\text { abnormalities. } \\
\text { Unconscious } \\
\text { patient: } \\
\text { Supine in Gurney } \\
\text { Backboard } \\
\text { undemeath patient } \\
\text { Call for Code } 3 \\
\text { Ambulance } \\
\text { Notify attending } \\
\text { MD } \\
\text { Begin CPR } \\
\text { Interventions } \\
\text { Gain IV access } \\
\text { Crash cart brought } \\
\text { to bedside } \\
\text { MD at bedside with } \\
\text { ACLS intervention } \\
\text { orders. } \\
\text { Prioritize, and } \\
\text { administer } \\
\text { appropriate } \\
\text { medications } \\
\text { ordered. } \\
\text { Continue to assess } \\
\text { patient condition. } \\
\text { Nursing staff } \\
\text { should remain with } \\
\text { patient in TTA } \\
\text { clinic. } \\
\text { Nursing staff } \\
\text { should remain calm } \\
\text { while performing } \\
\text { interventions. } \\
\text { Communicate for } \\
\text { increased team } \\
\text { work efforts. } \\
\text { a }\end{array}$ & $\begin{array}{l}\text { If the nursing team is } \\
\text { delays assessment, calling } \\
\text { for an ambulance, } \\
\text { notifying the physician, } \\
\text { starting CPR or } \\
\text { administering life-saving } \\
\text { medications in a timely } \\
\text { manner, the patient's } \\
\text { situation could further } \\
\text { decompensate quicker. } \\
\text { If the O2 saturation drops } \\
\text { below } 90 \% \text { without quick } \\
\text { follow up of interventions, } \\
\text { this could lead the patient } \\
\text { to suffer from lack of } \\
\text { oxygen deficiencies. }\end{array}$ & $\begin{array}{l}\text { The lead primary TTA } \\
\text { nurse or SRN can be } \\
\text { the lead nurse during } \\
\text { the code response. } \\
\text { The LVN and } \\
\text { secondary LVN will } \\
\text { assist in patient care } \\
\text { under the delegation of } \\
\text { the RN. The scribe will } \\
\text { begin documenting the } \\
\text { events of the code with } \\
\text { the interventions } \\
\text { performed and the } \\
\text { times completed. }\end{array}$ \\
\hline
\end{tabular}


CARDIAC EMERGENCY RESPONSE CASE SCENARIO

\section{Instructor Check List}

Pre-Scenario Check List

1. $\square$ Equipment is staged in simulation lab.

2. $\square$ The nurse learner has been oriented to the simulator.

3. $\square$ The nurse learner has been briefed on the expectations for the scenario.

4. $\square$ Participants understand their assigned character roles.

5. $\square$ The time frame Expectations for simulation met: $\square$ Yes $\square$ No.

6. $\square$ The time frame Expectations for debrief met: $\square$ Yes $\square$ No.

7. $\square$ Consent form has been signed by all participants.

\section{$\underline{\text { Post Scenario }}$}

\section{If you could change anything next time, what would it be?}

Comments:

\section{Simulation Assistant Name:}

Did the person provide excellent support for the scenario?

$\square$ Yes $\square$ No Comment

Instructor signature

Date 
CARDIAC EMERGENCY RESPONSE CASE SCENARIO

\section{Debriefing Guidelines}

Each nurse learning team will be given approximately 20-30 minutes to debrief. These groups will have an opportunity to sit together to communicate about the simulation training and their thoughts.

1. The nurse instructor will leave the simulation room and go to another location for a few minutes. This will allow participant teams to de-escalate emotions.

2. When the nurse instructor re-enters the room, acknowledge the emotions briefly. Validate the simulation training and discuss the reality that simulations are not $100 \%$ percent accurate in every emergency scenario when caring for actual patients. It depends on the medical team, equipment, and situation.

3. Ask each team for feedback. What went WELL in this simulation?

4. What DID NOT go well in this simulation?

5. If you could do it again, what would you do differently?

6. Summarize the groups communications and discussions, and re-iterate the highlights to let everyone know that their vocalizations were heard and noted for future references. 
APPENDIX F: PRE AND POST-TEST RESEARCH TOOL 


\section{Cardiac Emergency Medical Response Pre-Test}

\begin{tabular}{lll} 
Instructor: & Wang, D. NI & Years: \\
\cline { 2 - 2 } Class: & Simulation Cardiac EMR & Date: \\
\cline { 2 - 3 } Location: & Nursing Education & Results:
\end{tabular}

Pre-Scenario Check List

I have been oriented to the simulator

I understand the expectations of this simulation training

I understand the character role I will be playing

All of my questions about the simulation have been answered

I am aware that all necessary equipment for simulation training will be provided in simulation lab

\section{Instructions}

Please read each question carefully and then print the letter of the correct answer next to the question. Part I: Cardiac Pathophysiology

1) What is the blood vessel that returns oxygenated blood from the lungs to the heart?

a. Superior Vena Cava

b. Coronary Artery

c. Pulmonary Vein

d. Aorta

2) Jugular vein distention and chronic pedal edema indicate which type of heart failure?

a. Left Heart Failure

b. Right Heart Failure

c. Cardiac Tamponade

d. Heart Valve Disease

3)

The two lower chambers of the heart is called
a. Ventricles
b. Atriums
c. Myocardium
d. Node| 
Part II: Cardiac Knowledge Check

4) About how many cycles of CPR should you perform in $\mathbf{2}$ minutes?
a. 1
b. 2
c. 5
d. 7

6)

When an AED is applied, it will look for shockable rhythms in a patient. What are the

5) specific rhythms that will trigger the AED?

a. Asystole and Pulseless Electrical Activity

b. Ventricular Tachycardia and Ventricular Fibrillation

c. Atrial Fibrillation and Ventricular Tachycardia

d. Complete Heart Block and Atrial Fibrillation

With the MD at bedside during a cardiac arrest code, which dosage of epinephrine is anticipated to be given for ACLS purposes?

a. 1:100

b. $1: 1,000$

c. $1: 2000$

d. $1: 10,000$

You respond to a 71 year old patient in the housing unit who has altered mental status. He is semiconscious, has rapid, shallow respirations, and has a thready pulse. The cellmate states that the patient started with chest pains the day before, what should you do first?

7)

a. Call for a Ambulance

b. Assist with Ventilations

c. Take a Blood Pressure

d. Get the patient to the TTA clinic 
8) Which heart rhythm occurs when the heart beats rapid with erratic electrical pulses, and causes lower chambers of the heart to quiver instead of pumping blood .
a. Pulseless Electrical Activity
b. Ventricular Fibrillation
c. Atrial Flutter
d. Asystole

\section{Part III: Institutions Procedure for Cardiac Emergency Medical Response}

8)

Upon discovering a medical emergency, all summoning for assistance is appropriate EXCEPT

a. Two-Way Radio

b. Whistle

c. Personal Alarm

d. Leaving Patient and Returning to Clinic for Help

9) You should establish communication with custody and ensure scene safety before proceeding to the emergency patient location.

a. True

b. False

\section{Part IV: Simulation Nurse Training}

10) ___ Have you experienced using emergency simulation based training as a correctional nurse in the past?
a. often
b. once
c. never
d. can't recall

11) What are your thoughts about using simulation based training for emergency medical response learning and development? 


\section{Cardiac Emergency Medical Response Post-Test}

\begin{tabular}{llll} 
Instructor: & Wang, D. NI & Years: & \\
\cline { 2 - 2 } Class: & Simulation Cardiac EMR & Date: & \\
\cline { 2 - 2 } Location: & Nursing Education &
\end{tabular}

\section{Instructions}

Please read each question carefully and then print the letter of the correct answer next to the question. Part I: Cardiac Pathophysiology

1) What is the blood vessel that returns oxygenated blood from the lungs to the heart?
a. Superior Vena Cava
b. Coronary Artery
c. Pulmonary Vein
d. Aorta

2) Jugular vein distention and chronic pedal edema indicate which type of heart failure?
a. Left Heart Failure
b. Right Heart Failure
c. Cardiac Tamponade

d. Heart Valve Disease

3) The two lower chambers of the heart is called
a. Ventricles
b. Atriums
c. Myocardium
d. Node

\section{Part II: Cardiac Knowledge Check}

4) About how many cycles of CPR should you perform in $\mathbf{2}$ minutes?
a. 1
b. 2
c. 5
d. 7 
5)

When an AED is applied, it will look for shockable rhythms in a patient. What are the specific rhythms that will trigger the AED?

a. Asystole and Pulseless Electrical Activity

b. Ventricular Tachycardia and Ventricular Fibrillation

c. Atrial Fibrillation and Ventricular Tachycardia

d. Complete Heart Block and Atrial Fibrillation

6) With the MD at bedside during a cardiac arrest code, which dosage of epinephrine is anticipated to be given for ACLS purposes?
a. $1: 100$
b. $1: 1,000$
c. $1: 2000$
d. $1: 10,000$

You respond to a 71 year old patient in the housing unit who has altered mental status. He is semiconscious, has rapid, shallow respirations, and has a thready pulse. The cellmate states that the patient started with chest pains the day before, what should you

7) do first?

a. Call for a Ambulance

b. Assist with Ventilations

c. Take a Blood Pressure

d. Get the patient to the TTA clinic

8) Which heart rhythm occurs when the heart beats rapid with erratic electrical pulses, and causes lower chambers of the heart to quiver instead of pumping blood.
a. Pulseless Electrical Activity
b. Ventricular Fibrillation
c. Atrial Flutter
d. Asystole

\section{Part III: Institutions Procedure for Cardiac Emergency Medical Response}

8) EXCEPT

a. Two-Way Radio

b. Whistle 
c. Personal Alarm

d. Leaving Patient and Returning to Clinic for Help

You should establish communication with custody and ensure scene safety before

9) proceeding to the emergency patient location.

a. True

b. False

Part IV: Simulation Nurse Training

10) ___ Have you experienced using emergency simulation based training as a correctional nurse in the past?

a. often

b. once

c. never

d. can't recall

11) If you could change anything about simulation training next time, what would it be? 
APPENDIX G: NURSING PARTICIPANT RESEARCH CONSENT FORM 


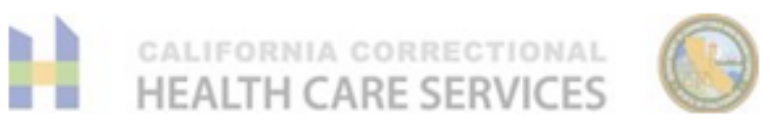 \\ Consent to Participate in a Research Study California Correctional Institution• Tehachapi, CA}

Title of Study: Curriculum development of California Correctional Institution (CCI) nursing staff performance during simulation training related to cardiac emergency response.

\section{Introduction}

You are being asked to take part in a research study of using high-fidelity simulation training curriculum for nursing performance development. The selection as a possible participant was identified through your involvement as a staff nurse at CCI. We ask that you read this form and ask any questions that may have before agreeing to be in the study.

\section{Purpose of Study}

- The purpose of the study is to use an innovative teaching technique to promote learning enhancements and self-growth for nurses during cardiac emergency patient care situations.

- Ultimately, this research may be published as contributions to correctional nursing presented as a paper.

\section{Description of the Study Procedures}

If you agree to be in this study, we will conduct a training session with you and other participating individuals. The training session will begin with a pre-test relevant to cardiac emergency patient care. Once the test is completed, you will be teamed up in groups of four, given acting roles, and completing a cardiac emergency simulation scenario in a simulation lab. After the scenario, all participants will be asked to take a cardiac emergency patient care posttest. We will then engage in a 30 minute debriefing group session allowing for simulation training experience feedback opportunities.

\section{Risks/Discomforts of Being in this Study}

- There are no physical reasonable, foreseeable (or expected) risks. There may be unknown risks.

\section{Benefits of Being in the Study}

- The benefits of participation is using simulation training to gain learning experiences in providing quality health care, improve patient outcomes, and achieve adequate OIG passing scores for Emergency Medical Response (EMR).

- Another benefit is your contribution efforts to correctional nursing research and being a part of the foundational research grounds for future studies.

\section{Confidentiality}

This study is anonymous. We will not be collecting or retaining any information about vour identity. The records of this study will be kept strictly confidential. We will not include any information in any report we may publish that would make it possible to identify you. All research actual data will be entered and stored in a password protected computer. 


\section{HEALTH CARE SERVICES}

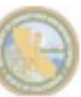

\section{Right to Refuse or Withdraw}

The decision to participate in this study is entirely up to you. You may refuse to take part in the study at any time without affecting your relationship with CCI. Your decision will not result in any loss or benefits to which you are otherwise entitled as an employee. You have the right not to answer any single question, as well as to withdraw completely from the interview at any point during the process.

\section{Right to Ask Questions}

The researcher conducting this study is Nurse Instructor Wang. Please ask any questions you have to me before, during or after the research. If you have any further questions about the study, at any time feel free to contact me at Dina.Wang@cdcr.ca.gov or by telephone at 661-8224402 ext. 3252 .

\section{Consent}

- Your signature below indicates that you have decided to volunteer as a research participant for this study, and that you have read and understood the information provided above. You will be given a signed and dated copy of this form to keep, along with any other printed materials deemed necessary by the study investigators.

Subject's Name (print):

Subject's Signature:

Date:

Investigator's Signature: Date: 